\title{
Synchronous polar winter starphotometry and lidar measurements at a High Arctic station
}

\author{
K. Baibakov ${ }^{1,2}$, N. T. O’Neill ${ }^{1}$, L. Ivanescu ${ }^{1}$, T. J. Duck ${ }^{3}$, C. Perro ${ }^{3}$, A. Herber ${ }^{4}$, K.-H. Schulz ${ }^{5}$, and O. Schrems ${ }^{2,4}$ \\ ${ }^{1}$ Centre d'Applications et de Recherches en Télédétection, Université de Sherbrooke, Sherbrooke, Canada \\ ${ }^{2}$ Dept. of Chemistry, University of Bremen, Bremen, Germany \\ ${ }^{3}$ Dept. of Physics and Atmospheric Science, Dalhousie University, Halifax, Canada \\ ${ }^{4}$ Alfred Wegener Institute for Polar and Marine Research, Bremerhaven, Germany \\ ${ }^{5}$ Dr. Schulz \& Partner GmbH, Buckow, Germany \\ Correspondence to: K. Baibakov (k.baibakov@usherbrooke.ca)
}

Received: 24 January 2015 - Published in Atmos. Meas. Tech. Discuss.: 19 February 2015

Revised: 22 July 2015 - Accepted: 23 July 2015 - Published: 18 September 2015

\begin{abstract}
We present recent progress on nighttime retrievals of aerosol and cloud optical properties over the PEARL (Polar Environmental Atmospheric Research Laboratory) station at Eureka (Nunavut, Canada) in the High Arctic $\left(80^{\circ} \mathrm{N}\right.$, $\left.86^{\circ} \mathrm{W}\right)$. In the spring of 2011 and 2012, a star photometer was employed to acquire aerosol optical depth (AOD) data, while vertical aerosol and cloud backscatter profiles were measured using the CANDAC Raman Lidar (CRL). We used a simple backscatter coefficient threshold $\left(\beta_{\text {thr }}\right)$ to distinguish aerosols from clouds and, assuming that aerosols were largely fine mode (FM)/sub-micron, to distinguish FM aerosols from coarse mode (CM)/super-micron cloud or crystal particles. Using prescribed lidar ratios, we computed FM and CM AODs that were compared with analogous AODs estimated from spectral star photometry. We found ( $\beta_{\mathrm{thr}}$ dependent) coherences between the lidar and star photometer for both FM events and CM cloud and crystal events with averaged, FM absolute differences being $<\sim 0.03$ when associated $R^{2}$ values were between 0.2 and 0.8 . A $\beta_{\text {thr }}$ sensitivity study demonstrated that zero crossing absolute differences and $R^{2}$ peaks were in comparable regions of the $\beta_{\text {thr }}$ range (or physical reasons were given for their disparity). The utility of spectral vs. temporal cloud screening of star photometer AODs was also illustrated. In general our results are critical to building confidence in the physical fidelity of derived, weak amplitude, star photometry AODs and, in turn, towards the development of AOD climatologies and validation databases for polar winter models and satellite sensors.
\end{abstract}

\section{Introduction}

The Arctic region, often viewed as an early indicator of climate change, has been recently undergoing major alterations including alarmingly increasing temperatures, retreating seaice cover and record low-ozone concentrations in the winter (Duarte et al., 2012; Manney et al., 2011; Moritz et al., 2002; Wang and Key, 2003). The current general circulation models (GCMs) underestimate the rate of sea-ice decline (Stroeve et al., 2011) and might differ substantially in terms of their projections (Kattsov and Källén, 2005). The differences between observations and model simulations and the scatter among models are due to the uncertainties in the underlying physical processes. In particular, the lack of understanding associated with a complexity of aerosol and cloud processes remains one of the major obstacles in accurately reproducing and predicting the Arctic climate (Inoue et al., 2006; Kattsov and Källén, 2005).

Aerosols can directly reduce the incoming shortwave radiation reaching the surface. Important examples in the Arctic include the effects of transported biomass burning, forest fire and volcanic plumes (e.g. Stone et al., 2008; Engvall et al., 2009; Young et al., 2012). In addition, aerosols play a profound indirect role serving as condensation nuclei for new clouds and modifying properties of already existing clouds. Understanding the nucleating role of aerosols in mixed-phase-type clouds, for example, remains an important research problem in terms of the climate impact of Arctic aerosols (McFarquhar et al., 2011; Prenni et al., 2007; Verlinde et al., 2007). For a particular atmospheric state, the 
net aerosol radiative effect depends on the aerosol type, size, plume height as well as underlying surface albedo and available short-wave radiation.

Because of its unique conditions, the Arctic has been an area of intense interest for aerosol studies. The multi-month daylight and darkness periods, isolated air masses and distinct temperature and humidity regimes result in complex and climatologically important atmospheric phenomena. At the same time, the availability of data, even simple meteorological measurements, is severely limited in the Arctic because of its remoteness and harshness. As a consequence, there are fewer than a dozen permanent Arctic stations with a continuous track of aerosol measurements. This record is augmented by intensive field campaigns with particular objectives concerning aerosols and aerosol-cloud interactions such as SHEBA/FIRE-ACE (October 1997-October 1998, Curry et al., 2000; Uttal et al., 2002), ASTAR (March-April 2000, Yamanouchi et al., 2005), ARCTAS (April, June-July 2008, Jacob et al., 2010), ISDAC (April 2008, McFarquhar et al., 2011), ARCPAC (April 2008, Brock et al., 2011) and POLARCAT (June-July 2008, Schmale et al., 2011).

The synergy of ground-based sunphotometer and lidar instruments has proven to be very effective in the analysis of day-time aerosol measurements. Sunphotometers (Shaw, 1983), based on the extinction of solar radiation, provide aerosol optical depth (AOD). AOD is an indicator of total aerosol column concentration and is the most important aerosol radiative parameter. A sunphotometer measures AOD in multiple channels and yields an estimation of particle abundance as well as aerosol size indicators (effective radius, $r_{\text {eff }}$ of submicron and supermicron modes for example) from the spectral information (O'Neill et al., 2003). Lidars measure time-gated returns of radiation backscattered by atmospheric particles: one can obtain vertical profiles of aerosol and cloud extinction and backscattering coefficient based on the time difference between the emitted and backscattered laser pulses (for a basic lidar principle see, for example, Carswell, 1983). Lidars also provide an indication of particle size from spectral channels and particle shape via the depolarization channels. The combined use of sunphotometers and lidar, accompanied by supplementary backward trajectories, satellite and other data, has been successfully applied to characterize Arctic aerosol events during the summer time (see, e.g., O'Neill et al., 2008a; Hoffmann et al., 2010; Stock et al., 2012).

The occurrence and characteristics of aerosols during the polar winter, however, have been studied to a much lesser extent. The radiation budget during this period is determined by longwave fluxes, which result in surface cooling and strong temperature inversions (Bradley et al., 1992). The end result is a very stable lower troposphere that hinders vertical heat and moisture transfer. It also reduces the aerosol deposition rate (e.g. Quinn et al., 2007). The polar winter is also associated with cloudless ice crystal precipitation, commonly termed "diamond dust". Contrary to initial conclu- sions (Curry et al., 1990), later studies suggest that diamond dust exhibits a negligible radiative effect (Intrieri and Shupe, 2004). However, reports on diamond dust occurrence and microphysical properties in the Arctic are very scarce. Furthermore, surrounding topography can have an important impact on the production of ice crystals. At the Eureka station, in the High Canadian Arctic, ice crystals are reported frequently during the winter period. Lesins et al. (2009) show that at least some of these ice crystals are due to the advection of snow from nearby ridges. Crystals formed in this fashion will exert a different radiative influence compared to classical diamond dust. A better characterization of polar winter atmospheric phenomena and aerosols in particular represents an important step towards a more comprehensive year-round view of Arctic processes.

One of the principal shortcomings of polar winter aerosol monitoring is the absence of AOD measurements. Star photometry and moon photometry, based, respectively, on the radiation from bright stars and the Moon, have consequently emerged as possible solutions to the problem. Recent studies show the potential of moon photometry measurements using sunphotometer-type instruments (Barreto et al., 2013; Berkoff et al., 2011). Despite inherent problems such as changing lunar brightness, moon photometry can currently provide AODs near full moon (Berkoff et al., 2011). The lunar cycle, however, limits the number of observations down to $30-40 \%$ of typical solar measurement observation numbers. Leiterer et al. (1995) introduced star photometry techniques based on extinction of bright-star radiation as a means of generating consistent and regular nighttime AOD measurements. Herber et al. (2002) successfully used a combination of sun- and star photometry to study multi-year AOD dynamics at Ny-Ålesund in the High Arctic. This work was based on daily AOD averages and did not focus on individual events or process-level sub-diurnal variations ${ }^{1}$. Furthermore, no coincident lidar data were available for the study period. Alados-Arboledas et al. (2011) showed the feasibility of combining star photometry and lidar data to study fresh biomass burning at mid-latitudes. No similar studies of simultaneously operating star photometers and lidars in the Arctic during the polar winter are currently available.

In 2011 an SPSTAR star photometer joined a Raman lidar as a part of the extensive instrumental suite for atmospheric measurements at the PEARL (Polar Environment Atmospheric Research Laboratory) in the High Canadian Arctic $\left(80^{\circ} \mathrm{N}, 86^{\circ} \mathrm{W}\right)$. Measurements were acquired at the sealevel site called OPAL (Zero Altitude PEARL Auxilary Laboratory). During the spring of 2011 and 2012 both instruments were operated in tandem in order to study optical properties of aerosols and thin clouds. The purpose of the current paper

\footnotetext{
${ }^{1}$ for simplicity we restrict our definition of "process-level" to the optical dynamics, timescale $\sim$ minutes: this is our own empirical determination in terms of significant AOD/lidar backscatter variation (as well as others; see Menut et al., 1999, for example ).
} 
is to show the capabilities of star photometer-lidar synergy in the Arctic as a tool for characterizing polar winter phenomena in terms of their optical properties. While both instruments are discussed, the focus of the work is on star photometry with additional details on lidar analysis given elsewhere. We present a process-level analysis of several events that were detected and studied using the combination of the two instruments. This event-based approach is essential to understanding the physics of underlying processes and should precede any statistical or climatological analysis. The results obtained are also important for validating CALIOP (CloudAerosol LIdar with Orthogonal Polarization) space-borne lidar observations acquired during the polar winter and, alternatively, for giving a spatial context to ground-based lidar and star photometer observations. The paper is structured as follows: Sect. 2 presents the description of the PEARL measurement site, Sect. 3 gives a brief technical overview of instrumentation, Sect. 4 contains important information on data processing and error analysis, while Sect. 5 describes the principal results obtained within the context of the current work. Finally, Sect. 6 serves as a summary with a review of the main findings.

\section{Measurement site}

PEARL is a CANDAC (CAnadian Network for the Detection of Atmospheric Change) research site collocated with the Eureka meteorological station in the High Canadian Arctic. It is located on Ellesmere Island, the northernmost island in the Canadian Arctic Archipelago. An overview of climate statistics at Eureka is given in Lesins et al. (2010). In particular, the average temperature during the coldest months January-March is $-37^{\circ} \mathrm{C}$ (idem). Strong surface-based temperature inversions are a consistent feature of the Eureka atmosphere. The average inversion temperature (the maximum temperature in the troposphere) is $-23^{\circ} \mathrm{C}$ while the average values of the inversion thickness and inversion lapse rate are $1200 \mathrm{~m}$ and $14^{\circ} \mathrm{C} \mathrm{km}^{-1}$, respectively (idem). The winters are extremely dry with an average precipitable water vapor column of less than $2 \mathrm{~mm}$ (idem). The surface air is very close to ice saturation during the winter, which explains the persistent presence of the ice crystals occurring at about $50 \%$ of the time (Lesins et al., 2010; Steinbring et al., 2012). The CANDAC instrument suite found at PEARL includes an array of atmospheric instruments for remotely probing the atmosphere from 0 to $100 \mathrm{~km}$ altitude. The optical suite for the measurement of aerosol properties includes an SPSTAR star photometer, a CRL (CANDAC Rayleigh-Mie-Raman) lidar, and a CIMEL CE-318 sunphotometer.

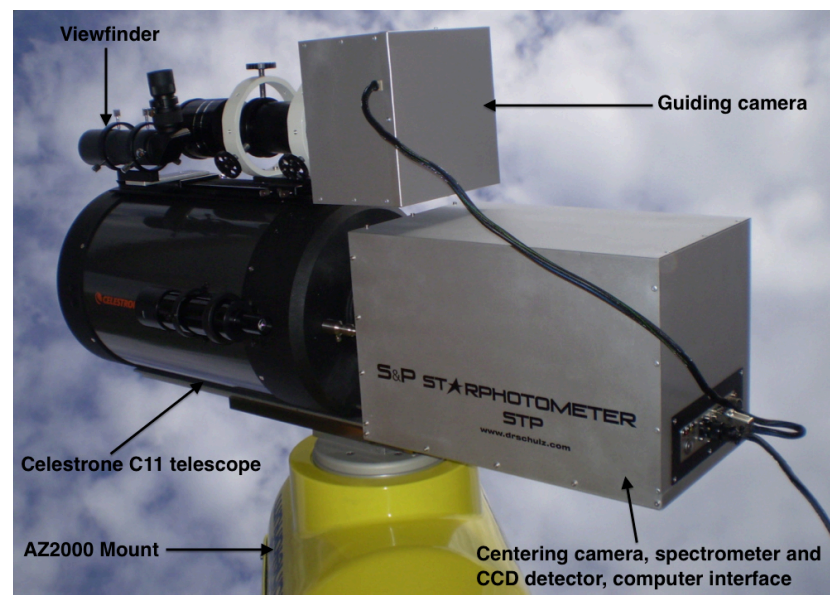

Figure 1. Principal components of SPSTAR star photometer.

\section{Instrumentation}

\subsection{Star photometer}

The SPSTAR star photometer, developed by Dr. Schulz and Partner GmbH acquires measurements of spectral star signals in 17 bands with nominal wavelengths of 419.9, 450.2, 469.2, 500.2, 531.7, 549.8, 605.4, 639.7, 676.1, 750.7, $778.9,862.3,933.5,943.2,952.8,1026.0$ and $1040.7 \mathrm{~nm}$ and an average spectral resolution of $2 \mathrm{~nm}$. The principal components of the SPSTAR are depicted in Fig. 1. These include a Celestrone C11 telescope (aperture/focal length $280 \mathrm{~mm} / 2800 \mathrm{~mm}$ ), a Baader AZ2000 altazimuth mount (Baader Planetarium GmbH), a viewfinder, two CCD cameras for centering a star's image on the measuring diaphragm and finally a measuring unit containing a grating spectrometer, a CCD detector and other secondary optics. The FOV (field of view) of the star photometer is approximately $0.15^{\circ}$.

\subsection{CRL lidar}

The CANDAC Rayleigh-Mie-Raman Lidar (CRL) measures elastic and Raman (vibrational and rotational transitions) backscatter at eight different wavelengths and polarizations using transmitted wavelengths of 532 and $355 \mathrm{~nm}$ with two pulsed Nd:YAG lasers. The scattered radiation from the eight detectors can be used to determine vertical profiles of aerosol backscatter and extinction, depolarization, temperature, and water vapor (Nott et al., 2012). CRL lidar receiver optical specifications are given in Table 1 . We note that the physical separation between the lidar and the star photometer was approximately $40 \mathrm{~m}$. 


\section{Data processing}

\subsection{Star photometry data processing}

\subsubsection{Calculation of star magnitudes}

Star photometry, like astronomy, uses logarithms of the measured star flux signal ${ }^{2}$ to compute star magnitudes. If $\mathrm{CN}$ is the number of counts (proportional to the incoming flux) for a particular star measured by the star photometer then the associated star magnitude $M$ is defined as follows:

$M=-2.5 \cdot \log _{10} \mathrm{CN}$.

In reality, the star photometer takes a series of flux measurements (usually five) of both a star and background immediately in the vicinity of the star. The $\mathrm{CN}$ value used in calculating the star magnitude (Eq. 1) is the difference between the mean star count (SC) and background count (HC):

$\mathrm{CN}=\mathrm{SN}-\mathrm{HC}$.

\subsubsection{Measurement principle}

The attenuation of solar light passing through the atmosphere can be expressed via Beer-Lambert's law (Shaw et al., 1973):

$I(z)=I_{0} e^{-m \tau(z)}$,

where $\mathrm{I}(\mathrm{z})$ is the solar irradiance as measured on the ground, $I_{0}$ is the extraterrestrial solar irradiance, $m$ is the air mass (e.g. Thomason et al., 1983) and $\tau$ is the total optical depth. In this work the term "air mass" refers to the optical air mass rather than synoptic air mass.

The value of $\tau$ can be decomposed as follows:

$\tau=\tau_{\text {ray }}+\tau_{\text {aer }}+\tau_{\mathrm{O}_{3}}+\tau_{\mathrm{NO}_{2}}+\tau_{\mathrm{H}_{2} \mathrm{O}}$

where $\tau_{\text {ray }}$ is the optical depth of molecular scattering (Rayleigh scattering), $\tau_{\text {aer }}$ is the optical depth due to aerosols (AOD) and $\tau_{\mathrm{O}_{3}}, \tau_{\mathrm{H}_{2} \mathrm{O}}, \tau_{\mathrm{NO}_{2}}$ are the optical depths due to absorption by ozone, water vapor, and nitrogen dioxide respectively.

In star photometry, the Beer-Lambert law, expressed in terms of stellar magnitude, becomes the following (Leiterer et al., 1995):

$M=M_{0}+1.086 \tau m$,

where $M$ is the measured magnitude on the ground (Eq. 1), $M_{0}$ is the extra-terrestrial instrumental magnitude, and we

\footnotetext{
${ }^{2}$ Different communities employ the label "flux" in different manners. Here, we employ flux as an indicator of the fundamental measurement made by a star photometer (i.e. radiance or radiative power per unit area per unit steradian per unit increment in wavelength). Since the field of view of the star photometer is larger than the angle subtended by the star, one can speak equally well of the stellar irradiance on a unit surface whose normal is parallel to the direction of the stellar beam.
}

have assumed, as per the previous section, that flux (irradiance) and the number of counts are proportional. The factor of 1.086 in Eq. (5) comes from the product $2.5 \log _{10} e$. Two measurement methods are currently used in star photometry: a two-star method (TSM) and a one-star method (OSM) which is an analogue to classical sun photometry.

\subsubsection{Two-star method (TSM)}

The two-star method is a relative approach that does not require calibration values. Applying Eq. (5) to each of the two stars and rearranging yields the following (after Leiterer et al., 1995):

$\tau=\frac{1}{1.086} \frac{\left(M_{1}-M_{2}\right)-\left(M_{01}-M_{02}\right)}{m_{1}-m_{2}}$.

The indices refer to the two stars (also termed "low" and "high" stars referring to their relative elevation) in the same part of the sky for which the air mass difference is sufficiently large $\left(\Delta m \geq 1\right.$, where $\left.\Delta m=m_{1}-m_{2}\right)$. Assuming that the magnitude difference is the same irrespective of the measurement instrument $M_{01}-M_{02}=M_{01}^{*}-M_{02}^{*}$, where $M_{0}^{*}$ refers to the extraterrestrial magnitudes taken from the astronomical catalogue of Alekseeva et al. (1996). Equation (6) can then be rewritten in the following form:

$\tau=\frac{1}{1.086} \frac{\left(M_{1}-M_{2}\right)-\left(M_{01}^{*}-M_{02}^{*}\right)}{m_{1}-m_{2}}$.

The star photometer constantly alternates between the two stars, providing AOD values every 5-6 min depending on the length of the star centering procedure. TSM can be prone to significant point-to-point variations if the atmosphere is not homogeneous (Baibakov, 2009).

\subsubsection{One-star method (OSM)}

Given a value of $M_{0}$ (see Sect. 4.2 on calibration), one can calculate the optical depth, $\tau$, for one star:

$\tau=\frac{M-M_{0}}{1.086 m}$.

The OSM temporal resolution is $2-3 \mathrm{~min}$. This method is also operationally simpler than the TSM, as only one star needs to be continually followed. The measurement accuracy of the extraterrestrial magnitudes for all wavelength channels ultimately determines the accuracy of the OSM AODs.

\subsubsection{Measurement stars and air mass range}

The results presented in this paper are based on the polar winter data sets obtained at Eureka in November 2010 and December 2011. The most frequently used measurement stars are listed in Table 2. The air mass range was between 1 and 2 for $95 \%$ of the measurements acquired in 2010-2011 and for $99 \%$ in 2011-2012. 
Table 1. CRL lidar receiver optical specifications. Based on Table 1 of Nott et al. (2012).

\begin{tabular}{lcl}
\hline Channel & Interference filter center wavelength $(\mathrm{nm})$ & Principal measurement \\
\hline $\mathrm{UV} \mathrm{elastic}_{\mathrm{UV} \mathrm{N}}$ & 354.72 & aerosols and clouds \\
$\mathrm{UV} \mathrm{H}_{2} \mathrm{O}$ & 386.67 & aerosols and clouds, water vapor \\
Visible elastic & 407.52 & water vapor \\
Visible $\mathrm{N}_{2}$ & 532.08 & aerosols and clouds \\
Visible depolarization & 607.46 & aerosols and clouds \\
Rotational Raman & 532 & aerosols and clouds \\
Low J & & \\
High J & 531.16 & atmospheric temperature \\
\hline
\end{tabular}

Table 2. Measurement stars most frequently used in polar winter star photometry data sets at Eureka in 2010-2011 and 2011-2012.

\begin{tabular}{lllcc}
\hline $\begin{array}{l}\text { Star (Harvard Revised } \\
\text { Photometry Catalogue) }\end{array}$ & Star name & Constellation & $\begin{array}{c}\text { Fraction of total } \\
\text { measurements in 2010-2011 (\%) }\end{array}$ & $\begin{array}{c}\text { Fraction of total } \\
\text { measurements in 2011-2012 (\%) }\end{array}$ \\
\hline 4295 & Merak & $\beta$ UMa & 79 & 26 \\
7001 & Vega & $\alpha$ Lyr & 13 & 40 \\
2421 & Alhena & $\gamma$ Gem & 5 & 0 \\
5191 & Alkaid & $\eta \mathrm{UMa}$ & 3 & 27 \\
\hline
\end{tabular}

\subsubsection{Spectral deconvolution algorithm (SDA) processing}

The star photometer AOD spectra were transformed into estimates of fine and coarse mode optical depth at a reference wavelength of $500 \mathrm{~nm}$ via the spectral deconvolution algorithm (SDA) of O'Neill et al. (2003). This method (whose output is also an AERONET (Aerosol Robotic Network) product) was employed, for example, by O'Neill et al. (2008a) and Saha et al. (2010) to analyze co-located sunphotometer and lidar data at Eureka and other Arctic stations. Its basic premise, that aerosol (and cloud) optics are largely driven by independent fine and coarse mode particle size distributions, permits a more fundamental understanding of both optical depths, lidar backscatter profiles and the link between the two. An error model defining the retrieval errors associated with SDA is given in the Appendix of O'Neill et al. (2003). A later technical memo (O'Neill et al., 2008b) corrects some errors in the equations given in the original paper. The component errors of the fine and coarse mode optical depths are driven by the nominal optical depth calibration error determined by AERONET personnel for all field instruments (see Holben et al., 1998 for a discussion of the AERONET calibration protocol). The fine and coarse mode retrieval errors are generally greater than or of the order of the approximate nominal calibration error. The SDA was applied to star photometry data for bands in the $419.9-862.3 \mathrm{~nm}$ wavelength range.

\subsubsection{Cloud screening of the star photometer data}

Photometry data needs to be routinely cloud screened to yield aerosol trends. Smirnov et al. (2000) describe an algorithm based on temporal AOD variations used in the AERONET global sun photometry network. Similarly, Pérez-Ramírez et al. (2012) apply temporal cloud screening procedures (such as a moving average test) to star photometry data sets. While this latter algorithm provides a consistent method to remove cloud-contaminated points, the approach and the necessary thresholds should be adapted based on the data set (D. PérezRamírez, personal communication, 2012). We expect, for example, that Arctic aerosol phenomena will be weaker in magnitude than those at mid-latitudes.

The filters employed in this work are described in Table 3 and partially mimic the methodology proposed by Smirnov et al. (2000) and Pérez-Ramírez et al. (2012). For the range condition, we have eliminated all negative AOD values as well as AODs higher than 0.35 at $500 \mathrm{~nm}$. The threshold of 0.35 was chosen as an upper Arctic-AOD-bound based on the statistics of Herber et al. (2002) and Tomasi et al. (2007). Clouds are significantly more variable in time than aerosols: hence one of the main cloud filtering tests is an AOD temporal derivative. Smirnov et al. (2000) defined a "triplet stability criterion" that employs three measurements taken $30 \mathrm{~s}$ apart over a total of a 1-min period. For a cloud-free atmosphere, the difference between the maximum and the minimum AODs should not exceed 0.02 , i.e. $\left(\tau_{\max }-\tau_{\min }\right)<0.02$, over this short time interval. However, there is no analogue to a triplet sampling rate of $30 \mathrm{~s}^{-1}$ for the Eureka star photometer: measurements can only be acquired at a sampling 
Table 3. Cloud filter protocol employed in this work. The three filters of the table are meant to be employed sequentially.

\begin{tabular}{lll}
\hline Filter name & Condition & Description \\
\hline 1. Range & $0<\tau<0.35$ & $\begin{array}{l}\text { AOD values should lie within a climatologically defined range. All the points outside the } \\
\text { range are removed. } \\
\text { The time of each measurement is taken as a middle of a } 1 \mathrm{~h} \text { interval. The point is eliminated } \\
\text { if the slope of the linear fit }(y=a t+b) \text { for all measurements contained in the } 1 \mathrm{~h} \text { interval } \\
\text { exceeds an empirically chosen threshold. } \\
\text { A point is eliminated, if its difference relative to the average value for the whole night } \\
\text { exceeds } 2.5 \text { standard deviations }(\sigma) . \text { The procedure is repeated until all the differences are } \\
\text { within } 2.5 \sigma .\end{array}$ \\
3. Outliers & $\begin{array}{l}\tau-\tau_{\text {avrg }}<2.5 \sigma \\
\end{array}$
\end{tabular}

rate of 3-10 $\mathrm{min}^{-1}$. Instead, Pérez-Ramírez et al. (2012) used an absolute difference of 0.03 between two consecutive AOD values (obtained, on average, every $5 \mathrm{~min}$ ) as a filtering condition, which essentially amounts to a rejection criterion of $|\mathrm{d} \tau / \mathrm{d} t|>0.006 \mathrm{~min}^{-1}$. This criterion turned out to be effective for many cloud scenes (except, of course, for temporally/spatially homogeneous clouds). The moving slope (which is effectively a time derivative computed from an hour-long regression about each optical depth measurement), and the pair-wise time derivative filters are similar and perform comparably, but the former is also sensitive to homogeneous clouds of moderate duration $(1-1.5 \mathrm{~h}$ duration). The pair-wise temporal derivative would not, on average, be sensitive to such variations since its decision protocol is limited to the (usually shorter) temporal range between any two measurements. We found that the empirically chosen $1 \mathrm{~h}$ period for the moving slope filter as well as the choice of $0.001 \mathrm{~min}^{-1}$ for the slope threshold performed well for the star photometry data sets. The moving slope threshold of $0.001 \mathrm{~min}^{-1}$ is considerably less than the $0.006 \mathrm{~min}^{-1}$ threshold employed for the pair-wise time derivative: this is meant to make up for the loss of high frequency sensitivity brought about by the regression over an hour. Additionally, 1 hour optical depth difference filtering is used by PérezRamírez et al. (2012) to avoid the inclusion of any outliers (while we depend on an AERONET type of (nightly) outlier filter defined in Table 3).

The application of the outliers filters listed above, amounted to our cloud-screening test adapted to polar winter star photometry: one presumes that outliers are very likely to be clouds because of the high frequency variations associated with the latter. We have adjusted the threshold from $3 \sigma$ of Smirnov et al. (2000) and Pérez-Ramírez et al. (2012) down to $2.5 \sigma$ given the observed variations in AOD.

It is expected that each filtering condition will have its own drawbacks. For example, the outliers filter will be dependent on the fraction of the cloud-free points in the time series, i.e. if the mean AOD value is too high, some cloud-contaminated values will be left in. When applied consecutively, however, we have found that most of the high-frequency variations associated with what we interpret as cloud features are removed.

Temporal cloud screening, nevertheless, can not eliminate homogeneous clouds with small point-to-point variations, nor can it avoid eliminating highly variable aerosol events such as the incursion of a strong (fine mode) smoke plume (O'Neill et al., 2003). A way to check the performance of the cloud filtering is to use the available spectral information to distinguish between clouds and aerosols (ibid). In fact, the coarse mode of the SDA is, for most Arctic cases, associated with large super-micron cloud particles ${ }^{3}$. If aerosol optics are dominated by fine mode aerosols (as they are in the Arctic) then the application of the method results in a de facto cloud screening algorithm whose output can be compared (or combined) with a temporal cloud screening algorithm. Quantitatively, one can evaluate the root-mean square difference, $\delta_{\mathrm{flt}, \mathrm{RMS}}$, between the fine mode AOD, $\tau_{\mathrm{f}}$ and the temporally cloud-filtered AOD, $\tau_{\mathrm{fft}}$ :

$\delta_{\mathrm{flt}, \mathrm{RMS}}=\sqrt{\frac{1}{N} \sum\left(\tau_{\mathrm{f}}-\tau_{\mathrm{flt}}\right)^{2}}$,

where $N$ is the total number of points in a time series.

We also compared the performance of the cloud filtering procedure with the lidar vertical profiles. In many cases, clouds tend to greatly enhance (and sometimes saturate) the lidar backscatter return. Evaluating the vertically integrated lidar signal (lidar optical depth) relative to the $\tau_{\text {fft }}$ (while being able to visually confirm the presence of cloud from its typically unique appearance as a high frequency, high intensity perturbation in the backscatter coefficient profile) is thus a natural way to ensure the quality of cloud screening.

The cloud-screening algorithm presented here was predominantly developed for constructing intra-annual and inter-annual aerosol climatologies. With the exception of Sect. 5.5, we chose not to use cloud screening for the processlevel (minutes timescale) analysis presented in Sect. 5, in

\footnotetext{
${ }^{3}$ The coarse mode can also be associated with large-size aerosols, such as desert dust, volcanic ash and marine salt. However such events are, in our experience, relatively rare at Eureka and/or seasonally constrained.
} 
order to preserve AOD variations in coarse mode dominant events.

\subsection{Star photometry calibration}

A more detailed treatment of star photometer calibration is left to Ivanescu (2015). Here we present only a brief discussion.

Despite the obvious advantage of the TSM not requiring a star photometer calibration, the OSM is considered to be the main operational method. The OSM does not necessitate atmospheric homogeneity and has a higher sampling rate. Furthermore, A. Gröschke (unpublished data) argues that the accuracy and error analysis is not straightforward for the TSM, given its differential nature.

In order to make measurements with the OSM or extract individual AODs related to the low and high stars of the TSM, one needs to derive extraterrestrial star magnitudes, i.e. magnitudes that a star photometer would measure outside of the atmosphere ( $M_{0}$ in Eq. 8). This can be done either by using Langley-type procedures (Shaw et al., 1973) or by calculations from the TSM data. Langley calibration in the Arctic, however, is problematic as it takes many hours for some of the measurement stars to go through a sufficient optical air mass change (Herber et al., 2002). This results in variable measurement conditions and, correspondingly, calibration inaccuracies. Consequently, calibration using a priori acquired TSM data is the de facto calibration method in the Arctic.

Extra-terrestrial star magnitudes can be calculated from TSM data using Eq. (5). Theoretically, only one TSM point is needed to derive $M_{0}$ for a particular star. In practice however, one has to analyze at least several nights of measurements, and preferably the entire data set, to ensure the consistency and stability of the calibration values (A. Gröschke, unpublished data). The problem with Eq. (5) is that the analysis has to be made separately for each measurement star, which is a lengthy and tedious procedure. One solution is to use a procedure akin to the "calibration transfer" proposed by PérezRamírez et al. (2008a) in which several additional stars are also measured during the calibration process (either Langley or TSM). $M_{0}$ for those stars can then be easily calculated using Eq. (5) by assuming the average value of $\tau$ obtained during the calibration procedure.

We employed the star catalogue transfer function or calibration constant, $C$, to consolidate the ensemble of our multistar measurements for calibration purposes (Ivanescu, 2015). $C$ is defined as

$C=M_{0}^{*}-M_{0}$.

In theory, this allows every TSM measurement to be used to derive calibration values common to all stars. In practice, however, some potential calibration values need to be removed because of the inherent variability in the TSM data (due for example, to contamination by clouds, ice deposi- tion on the optics and instrumental temperature variability). In this work, we imposed the following conditions for a point to qualify for calibration: (a) the point is not marked as cloud by the cloud screening procedure and (b) the error associated with the measurement $\left(\delta_{\tau}\right)$, does not exceed a certain threshold. In (b) we used $\delta_{\tau} \leq 0.005$ (significantly less than the 0.01-0.02 accuracy expected for normal field measurements) as a conservative threshold for ensuring good calibration conditions. The 0.01-0.02 range is, for example, often quoted for AERONET field instruments (Eck et al., 1999). The resulting calibration values were chosen as averages of the points satisfying all the criteria. The mean standard deviation of $C(\delta C)$ for the bands in the range 420-862 nm was 0.027 . This corresponds to a mean relative flux error of 0.025 $\left(\delta F_{0} /\left\langle F_{0}\right\rangle\right.$ of Appendix A, Eq. A13).

\subsection{Estimation of AOD errors and uncertainties in star photometry measurements}

\subsubsection{Sources of calibration, measurement and processing errors}

A variety of internal (related to the photometer itself) and external (related to the environment and pointing accuracy) factors can result in star photometer measurement errors and inconsistencies. Most of the instrumental issues, such as detector linearity and temperature sensitivity as well as dark current, are discussed in detail in Pérez-Ramírez et al. (2008a, b) and A. Gröschke (unpublished data). Star photometry AOD errors, nevertheless, can result from other sources. For example, TSM measurements are sensitive to the horizontal homogeneity of the atmosphere while the accuracy of the OSM measurements is directly dependent on the quality of the calibration values. Furthermore, the AOD retrieved from some of the SPSTAR visible bands can suffer from insufficiently accurate ozone (and possibly $\mathrm{NO}_{2}$ ) correction, while the infrared channels can be affected by water vapor absorption.

Setting aside the cases of the water-vapor sensitive near infrared (NIR) channels (which we did not employ in this work) the most important gaseous absorber in the visible spectra region is ozone. Using an estimated ozone uncertainty of 31 DU (standard deviation from Eureka ozonesonde data) will result in a corresponding standard deviation $\left(\delta_{\tau, \text { ozone }}\right)$ of 0.004 at $605 \mathrm{~nm}$ and 0.001 at $500 \mathrm{~nm}$ (assuming a random distribution in ozone concentration errors). This is substantially less than the nominal star photometry calibration error of $\delta_{\tau, \mathrm{cal}}=0.01$ but is not insignificant.

The value of $\mathrm{NO}_{2}$ optical depth that we employed for our $\mathrm{NO}_{2}$ corrections was $\tau_{\mathrm{NO}_{2}}=0.003$. Measurements over Eureka during the late polar winter of 2004 showed $\mathrm{NO}_{2}$ columnar abundances between approximately 1.0 and $2.0 \times$ $10^{15}$ molecules $\mathrm{cm}^{-2}$ (Kerzenmacher, 2005). This yields a range of $\tau_{\mathrm{NO}_{2}}$ between approximately 0.0005 and 0.001 for a nominal absorption cross section of $5 \times 10^{-19} \mathrm{~cm}^{2}$ applied to wavelength channels from the UV to the blue-green portion 
of the spectrum (O'Neill, 1999). A conservative estimate of $100 \%$ for the relative $\mathrm{NO}_{2}$ optical depth error (i.e. an absolute error of 0.003) will encompass the late winter Eurekabased estimates of $\tau_{\mathrm{NO}_{2}}$.

The estimated error in the Rayleigh optical depth as given by Frohlich and Shaw (1980) is $0.001 \%$ for the wavelength range of 300-900 nm: this yields a maximum Rayleigh optical depth error of 0.00043 at $380 \mathrm{~nm}$. While this may be a bit optimistic for the Arctic it is most likely of the correct order of magnitude and therefore negligible compared to $\mathrm{O}_{3}$ and $\mathrm{NO}_{2}$ errors. Rayleigh optical depths are also pressure corrected: we roughly estimate the uncertainty associated with the pressure correction to be on the order of Frohlich and Shaw's $0.001 \%$ relative error $(\sim 1 \mathrm{hPa}$ over $1013 \mathrm{hPa})$.

We acknowledge that retrieved AOD values can be affected by rapidly changing optical air mass at very large zenith angles (or, consequently, small star elevation angles). Russell et al. (2005) for example, discuss AOD uncertainties for air masses of $\sim 30-40$. However, because of the small air mass values used in this work (between 1 and 2, see Sect. 4.1.5), we consider uncertainties due to air mass calculations as negligible compared to other sources of error.

Some of the other factors that might effect AOD measurements include imprecision in star pointing and tracking (resulting in either underestimated star signal or overcompensated background correction), vibrations due to winds (> $8 \mathrm{~m} \mathrm{~s}^{-1}$ ), light pollution due to Moon or artificial lightning and ice deposition on the telescope.

\subsubsection{Estimated total error in $\tau_{\text {aer }}$}

From Eq. (4) the total AOD error, $\delta_{\tau_{\text {aer }}}$ is a function of the errors in all the component parameters employed in its retrieval. Expressing Eq. (3) in terms of numerical counts, $\mathrm{CN}$ and $\mathrm{CN}_{0}, \delta_{\tau_{\text {aer }}}$ can be estimated as following (see Appendix A for details):

$\delta\left(\tau_{\text {aer }}\right)=$

$\sqrt{\left(\frac{1}{m}\right)^{2}\left\{\left(\frac{\delta\left(\mathrm{CN}_{0}\right)}{\left\langle\mathrm{CN}_{0}\right\rangle}\right)^{2}+\left(\frac{\delta(\mathrm{CN})}{\langle\mathrm{CN}\rangle}\right)^{2}\right\}+\delta^{2}\left(\tau_{\mathrm{O}_{3}}\right)+\delta^{2}\left(\tau_{\mathrm{NO}_{2}}\right)+\delta^{2}\left(\tau_{\mathrm{H}_{2} \mathrm{O}}\right)}$,

where $\frac{\delta\left(\mathrm{CN}_{0}\right)}{\left\langle\mathrm{CN}_{0}\right\rangle}$ is the calibration error, $\frac{\delta(\mathrm{CN})}{\langle\mathrm{CN}\rangle}$ the measurement error, $\left\langle\mathrm{CN}_{0}\right\rangle$ and $\langle\mathrm{CN}\rangle$ are the average values of $\mathrm{CN}$ and $\mathrm{CN}_{0}$ and $\delta\left(\tau_{\mathrm{O}_{3}}\right), \delta\left(\tau_{\mathrm{NO}_{2}}\right), \delta\left(\tau_{\mathrm{H}_{2} \mathrm{O}}\right)$ the errors associated with the estimation of ozone, $\mathrm{NO}_{2}$ and $\mathrm{H}_{2} \mathrm{O}$ optical depths respectively. This yields an OSM error estimate of $\delta\left(\tau_{\text {aer }}\right)=0.03$ for a typical air mass value of $m=1$.

\subsubsection{AOD error due to incomplete cloud screening}

The estimate of $\delta_{\tau_{\text {aer }}}$ above is for the list of error contributions that are readily quantified with some coarse degree of accuracy (or they can be highly inaccurate but very small). It precludes "catastrophic errors" such as significant ice condensation on the optics or serious tracking errors in the star measurement or in the background measurement modes. The oftentimes inadequate nature of temporal cloud screening remains an error source which is highly variable. If we anticipate the results of our spectral vs. temporal cloud screening comparison (Sect. 5.5) in the presence of (spatially inhomogeneous) clouds whose presence is readily filtered out (Fig. 9), then we can at least get out an order-of-magnitude error associated with the shortcomings of temporal cloud screening in the presence of optically thin clouds. Based on the RMS computations for the illustrative case of Fig. 9 we obtain $\delta\left(\tau_{\text {aer,post-cloud-screening }}\right) \lesssim 0.03$, a number which will be inflated by, for example, inaccuracies in the retrieval of aerosol fine mode optical depth, $\tau_{\mathrm{f}}$, and the possible presence of thin homogeneous cloud that escapes temporal cloud screening. This estimate is an attempt to describe a worst case scenario: in the absence of competitive coarse mode signal, $\delta\left(\tau_{\text {aer,post-cloud-screening }}\right)$ will be significantly smaller.

\subsection{CRL processing}

The lidar return contains information about the atmosphere in terms of the backscatter and extinction coefficients, $\beta(z)$ and $\kappa(z)$. The former describes how much light is scattered into the backward direction and determines the strength of the return lidar signal from the sampling volume at altitude $z$. The extinction coefficient describes the combined capacity of all particles and molecules to diminish the laser beam intensity in the sampling volume at altitude $z$. The profile of the extinction coefficient between the receiver and the sampling volume acts to attenuate the outgoing and return signal from the sampling volume at altitude $z$. Assuming that the light is scattered mostly by air molecules (index " $m$ "') and aerosols (index "a"), $\beta(z)$ can be expressed as follows:

$\beta(z)=\beta_{\mathrm{m}}(z)+\beta_{\mathrm{a}}(z)$.

One distinguishes between elastic (Rayleigh) and inelastic (Raman) scattering. In the former case, the frequency of the scattered photon is the same as the frequency of the incident photon. Raman scattering (which a Raman lidar such as CRL makes use of) changes the internal energy state of specific types of molecules in the path of the beam. The resulting frequency shift of the scattered photon can be used to separate molecules from aerosols as the latter undergo only elastic scattering.

There are two techniques used for the purpose of determining the aerosol backscatter coefficient for the CRL. The first is the Klett inversion (Klett, 1981), which is applied to the elastic scattering channel at $532 \mathrm{~nm}$. The second technique, the ratio technique (Ansmann and Müller, 2005), uses the elastic scattering channel $(532 \mathrm{~nm})$ and a Nitrogen Raman scattering channel $(607 \mathrm{~nm})$ to obtain profiles of backscatter coefficient. The Klett inversion requires an estimation of the aerosol extinction to backscatter ratio (or lidar ratio, $S_{\mathrm{a}}$ ), which can be difficult to estimate. The ratio technique how- 
ever is much noisier due to the low scattering cross section of Raman-scattered radiation.

To make meaningful comparisons between extinction based star photometer (whose output is optical depth) and lidar, one needs an estimate of the lidar ratio to convert the backscatter coefficient to extinction coefficient and subsequently permit the integration of the latter vertical profile to obtain lidar optical depth. An alternate ratio technique, by Ansmann et al. (1992), which employs the transmission of the Raman channel to directly measure extinction coefficient also suffers from the weak and noisy nature of the Raman channel as well as the fact that a noise-sensitive vertical derivative has to be applied to yield extinction coefficient.

A common issue with lidar monitoring is the incomplete overlap region. The overlap region is defined as a region where the field of view of the receiving system does not fully capture the backscatter from the transmitted radiation. This will occur for a range of altitudes near the surface. By combining both the Klett and ratio techniques, a correction can be applied to the Klett inversion as shown by Wandinger and Ansmann (2002). The ratio technique should not suffer from overlap effects due to the two detectors (that measure the elastic and inelastic signal ratios being calculated) theoretically having the same incomplete overlap region (idem). In reality, however, this is not the case, and a correction is applied to the ratio technique analysis by using "clear-sky" measurements (minimal aerosol and cloud) from which the profile of aerosol backscatter would be weak. Applying these overlap corrections allows the CRL to measure down to approximately $200 \mathrm{~m}$ for both techniques.

The CRL also measures linear depolarization ratio (DR) defined as a ratio of the orthogonal and parallel components of the backscattered light. DR is primarily dependent on particle habit (i.e. the gamut of possible shapes between spherical particles and complex crystals) but can also be used as a means of discriminating fine mode particles from coarse mode particles (see for example O'Neill et al., 2012). Consequently, DR could potentially be used for partial cloud/ice crystals screening validation. The CRL DR hardware and processing algorithms, however, are still in development and so only sporadic measurements are available. Only DR data obtained on 21 February 2011 were used for the purposes of this paper.

\subsection{Lidar optical depth computations}

\subsubsection{Simple threshold approach for aerosol/cloud discrimination}

As a part of the analysis, we integrated the lidar profiles to calculate lidar fine, coarse mode and total optical depths (we adopted the notation whereby primed optical depths $\left(\tau_{\mathrm{f}}^{\prime}, \tau_{\mathrm{c}}^{\prime}, \tau_{\mathrm{a}}^{\prime}=\tau_{\mathrm{f}}^{\prime}+\tau_{\mathrm{c}}^{\prime}\right)$ are derived from lidar profiles, whereas unprimed optical depths $\left(\tau_{\mathrm{f}}, \tau_{\mathrm{c}}\right.$ and $\left.\tau_{\mathrm{a}}=\tau_{\mathrm{f}}+\tau_{\mathrm{c}}\right)$ are derived from the star photometry data). For the lidar compo- nents we assumed lidar ratios based on the following binary fine/coarse classification scheme. Features with backscatter coefficient values at $532 \mathrm{~nm}$ higher than a specific threshold ( $\beta_{532, \text { thr }}$ or simply $\left.\beta_{\text {thr }}\right)$ were considered clouds or ice crystals and assigned to a cloud/ice crystal class while all other backscatter coefficient samples were classified as fine mode aerosols (implicit in this latter assignment is the assumption that aerosol optical activity is dominated by fine mode aerosols). Cloud/ice crystal samples were assigned a lidar ratio value of $S_{\mathrm{c}}=20 \mathrm{sr}$. This value is a typical cloud lidar ratio; it is, for example, contained within the 1925 sr range defined in the CALIPSO data processing algorithm (ASDC, 2013). All non-cloud layers were assigned a value of $S_{\mathrm{f}}=71 \mathrm{sr}$ (corresponding to the CALIOP class "urban/industrial pollution", idem, and, for example, a value that is not far from the value of $59 \mathrm{sr}$ employed by O'Neill et al. (2012) for volcanic sulfates over Eureka). While aerosols exhibit a fairly large natural variation in $S_{\mathrm{f}}$, the chosen value was found to perform well for most scenes observed at Eureka.

\subsubsection{Sensitivity study}

To select a value of $\beta_{\text {thr }}$ that does not produce a significant bias in favor of either clouds or aerosols, we performed a sensitivity study for all events that were investigated in this study: 21 February 2011, 9 and 10 March 2011 and 13, 14 and 15 March 2012 (the detailed discussion of these events is presented in Sect. 5). We varied $\beta_{\mathrm{thr}}$ from $1 \times 10^{-10} \mathrm{~m}^{-1} \mathrm{sr}^{-1}$ (all/most features classified as clouds) to $1 \times 10^{-3} \mathrm{~m}^{-1} \mathrm{sr}^{-1}$ (all/most features classified as aerosols) and studied the variation of $\left\langle\tau_{x}^{\prime}\right\rangle-\left\langle\tau_{x}\right\rangle$ and $R_{x}^{2}$ (where the angle brackets " \langle\rangle " indicate an average, the subscript $x=\mathrm{f}, \mathrm{c}$ or a, $R_{x}^{2}$ is the coefficient of determination and where the averages and the $R_{x}^{2}$ values were evaluated across the duration of the measuring period). Our sensitivity study was focused more on fine mode aerosols (which, as discussed above, generally means aerosols in the absence of any significant presence of coarse mode aerosols) since this is our principle research motivation and since fine mode aerosol variation is generally more subtle and difficult to detect in the Arctic.

\section{Illustration using the 9 March case study}

Figure 2 illustrates the results of the sensitivity study for 9 March 2011. The top plot of Fig. 2a shows the fixed star photometer optical depth means $\left(\left\langle\tau_{\mathrm{f}}\right\rangle,\left\langle\tau_{\mathrm{c}}\right\rangle\right.$ and $\left\langle\tau_{\mathrm{a}}\right\rangle$ averages taken across the 9 March measuring period) and the computed values of $\left\langle\tau_{\mathrm{f}}^{\prime}\right\rangle,\left\langle\tau_{\mathrm{c}}^{\prime}\right\rangle$ and $\left\langle\tau_{\mathrm{a}}^{\prime}\right\rangle$ varying as a function of $\beta_{\mathrm{thr}}$ while the middle plot shows the difference between these means (note that $\left\langle\tau_{\mathrm{f}}\right\rangle$ and $\left\langle\tau_{\mathrm{c}}\right\rangle$ are practically superimposed; the relatively large value of $\left\langle\tau_{\mathrm{c}}\right\rangle$, as will be discussed in Sect. 5.1, is due to thin-cloud contamination). As expected $\left\langle\tau_{\mathrm{f}}^{\prime}\right\rangle \rightarrow 0$ when $\beta_{\text {thr }}$ is very small, and the classification algorithm declares all particles to be clouds while $\left\langle\tau_{\mathrm{c}}^{\prime}\right\rangle \rightarrow 0$ when 

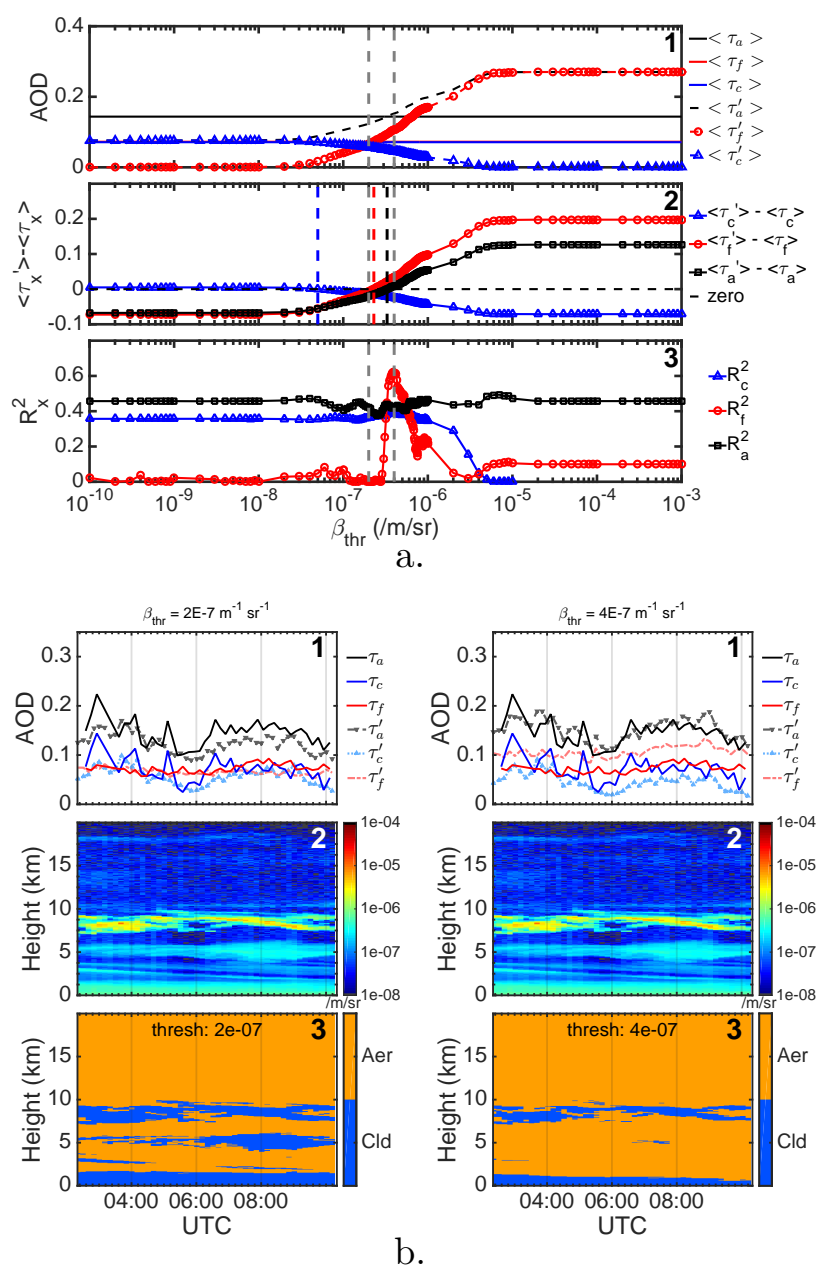

Figure 2. Backscatter threshold sensitivity $\left(\beta_{\mathrm{thr}}\right)$ study for the 9 March 2011 Eureka aerosol event. (a) Top graph: event-averaged lidar and star photometer AODs as a function of the cloud discrimination threshold $\beta_{\mathrm{thr}}$. Middle graph: differences between star photometry and lidar event-averaged AODs. The vertical dotted lines indicate values of $\beta_{\mathrm{thr}}$ for which $\left\langle\tau_{\mathrm{f}}\right\rangle=\left\langle\tau_{\mathrm{f}}^{\prime}\right\rangle,\left\langle\tau_{\mathrm{c}}\right\rangle=\left\langle\tau_{\mathrm{c}}^{\prime}\right\rangle$ and $\left\langle\tau_{\mathrm{a}}^{\prime}\right\rangle=$ $\left\langle\tau_{\mathrm{a}}^{\prime}\right\rangle$ respectively. Bottom graph: coefficients of determination between the lidar and star photometry optical depths across the duration of the event. The two vertical grey lines indicate $\beta_{\text {thr }}$ thresholds used in (b); (b) panes 1: star photometry and lidar fine mode, coarse mode and total AODs $(500 \mathrm{~nm})$ corresponding to the $\beta_{\text {thr }}$ values indicated above the panes; panes 2: CRL $532 \mathrm{~nm}$ backscatter crosssection for the two $\beta_{\text {thr }}$ values; panes 3: cloud/aerosol classification for the two $\beta_{\mathrm{thr}}$ values.

$\beta_{\text {thr }}$ is very large and the classification algorithm declares all particles to be fine mode aerosols.

The bottom graph of Fig. 2a shows the different components of $R_{x}^{2}$ ( $\tau_{x}^{\prime}$ vs. $\tau_{x}$ ) varying as a function of $\beta_{\mathrm{thr}}$. One can observe the promising result that both the $\beta_{\mathrm{thr}}\left(\left\langle\tau_{\mathrm{f}}^{\prime}\right\rangle-\left\langle\tau_{\mathrm{f}}\right\rangle=\right.$ $0)$ zero crossing (red dotted vertical line of the middle graph) and $\beta_{\mathrm{thr}}\left(R_{\mathrm{f}, \text { peak }}^{2}\right)$ are of the same order of magnitude while noting the more disconcerting result that the rapid variation of $R_{\mathrm{f}}^{2}$ implies that the difference is a compromising problem. However, as discussed in the next section, we can play upon the relatively large uncertainties in the star photometer and lidar optical depths to define a large zero crossing region which encompasses the peak in $R_{\mathrm{f}}^{2}$.

Figure $2 \mathrm{~b}$ provides insight into the detailed behavior at two critical values of $\beta_{\text {thr }}$ : a value of $2 \times 10^{-7} \mathrm{~m}^{-1} \mathrm{sr}^{-1}$ which corresponds to a near zero value of $R_{\mathrm{f}}^{2}$ and a value of $4 \times 10^{-7} \mathrm{~m}^{-1} \mathrm{sr}^{-1}$ which corresponds approximately to $\beta_{\mathrm{thr}}\left(R_{\mathrm{f}, \text { peak }}^{2}\right)$. The top pane contains total, fine and coarse mode AODs from the SDA at $500 \mathrm{~nm}\left(\tau_{\mathrm{a}}, \tau_{\mathrm{f}}\right.$ and $\tau_{\mathrm{c}}$ respectively) and the lidar AODs at $532 \mathrm{~nm}\left(\tau_{\mathrm{a}}^{\prime}\right.$, $\tau_{\mathrm{f}}^{\prime}$ and $\tau_{\mathrm{c}}^{\prime}$ respectively), while pane 2 shows lidar backscatter cross-section profiles at $532 \mathrm{~nm}$. Values of $\tau_{\mathrm{f}}^{\prime}$ and $\tau_{\mathrm{c}}^{\prime}$ were calculated in accordance with Sect. 4.1.5 where the binary lidar ratio assignments are determined from the aerosol/cloud classification of pane 3.

If one compares the $\tau_{f}^{\prime}$ variation of Fig. $2 b$ with the backscatter profiles and, in particular, the classification panes, it is clear that the increase in $\tau_{\mathrm{f}}^{\prime}$ from left pane 1 to right pane 1 is due to the "gain" of aerosols in the plume located at around $5 \mathrm{~km}$ (also keep in mind that the $\left\langle\tau_{\mathrm{f}}\right\rangle$ component of the comparison is fixed). This plume (which we hypothesize, from experience, to actually be of aerosol nature) is responsible for the right to left increase in $\tau_{\mathrm{f}}^{\prime}$ (from the left hand pane 1 to the right hand pane 1) and the greater thickness of the plume in the latter part of the day is responsible for the proportionate (right hand pane 1) increase in $\tau_{\mathrm{f}}^{\prime}$ over that period (compared to the quasi constant value of $\tau_{\mathrm{f}}^{\prime}$ in the left hand pane). This increase across the measurement period is sufficient to augment $R_{\mathrm{f}}^{2}$ from a negligible value of 0.02 to a significant value of 0.62 (more details are given in Sect. 5.1). It is our contention that the most robust arbiter of physical truth is arguably $R_{x}^{2}$ (and $R_{\mathrm{f}}^{2}$ in the particular case of fine mode aerosols) because it can show a correlation of independent optical data and because it is less dependent on calibration and algorithmic artifacts. The $\left\langle\tau_{\mathrm{f}}^{\prime}\right\rangle-\left\langle\tau_{\mathrm{f}}\right\rangle$ differences of Fig. 2a are more readily swayed by the relatively large absolute uncertainties in $\tau_{\mathrm{f}}$ due to calibration and algorithmic shortcomings as well as the uncertainties in $\tau_{\mathrm{f}}^{\prime}$ due to problems such as errors in the assigned value of $S_{\mathrm{f}}$ and errors in the the lidar calibration procedure. More details on the types of systematic errors observed between the components of the lidar and star photometer AODs are given in Sect. 4.5.3 and in the event analysis of Sect. 5.

Some comments also need to be added concerning the general behavior of the $R_{x}^{2}$ curves in Fig. 2a. $R_{\mathrm{c}}^{2}$ remains moderately large and nearly constant and then drops off for $\left.\beta_{\text {trh }}\right\rangle \sim 1 \times 10^{-6}$. This reflects the fact that the backscatter coefficients of what we believe to be clouds between 7 and $10 \mathrm{~km}$ stand out quite distinctly until their rather large threshold value is surpassed and all samples are declared to be fine mode aerosols. Beyond this point, the values of $R_{\mathrm{a}}^{2}$ remain moderately large and constant. Since all backscatter samples 
have, at this point, been declared to be fine mode aerosols, the clouds between 7 and $10 \mathrm{~km}$ become artificially labeled as fine mode aerosols with an attendant artificial trend of $\left\langle\tau_{\mathrm{f}}^{\prime}\right\rangle \rightarrow\left\langle\tau_{\mathrm{a}}^{\prime}\right\rangle$ as the cloud particles are progressively attributed an excessive lidar ratio of $S_{\mathrm{f}}=71 \mathrm{sr}$. It can also be observed in Fig. 2a that this case of artificially large $\left\langle\tau_{a}^{\prime}\right\rangle$ is characterized by $R_{\mathrm{a}}^{2}$ values that are identical to $R_{\mathrm{a}}^{2}$ values when $\beta_{\text {thr }}$ is very small; the only differences between the two artificial cases of ostensibly pure fine and coarse mode cases are the two different values of lidar ratio (and so the correlation with $\tau_{\mathrm{a}}$ is identical).

\section{Ranges of optically acceptable $\beta_{\text {thr }}$}

Figure $3 \mathrm{a}$ shows a conceptual representation of $\beta_{\mathrm{thr}}$ uncertainty as a function of a presumed uncertainty in the differences of the means for each of the three components. In the application of this concept to $\left\langle\tau_{x}^{\prime}\right\rangle-\left\langle\tau_{x}\right\rangle$ plots such as the middle graph of Fig. 2a, we assumed an error equal to the nominal uncertainty of 0.03 in the star photometer optical depths as per Sect. 4.3.2 and applied it to all analyzed events to obtain the top graph of Fig. 3b. One can observe that the $\beta_{\text {thr }}$ ranges of $\left\langle\tau_{\mathrm{f}}^{\prime}\right\rangle-\left\langle\tau_{\mathrm{f}}\right\rangle$ are clustered near the $\beta_{\text {thr }}$ value of $4 \times 10^{-7} \mathrm{~m}^{-1} \mathrm{sr}^{-1}$ represented by the dashed, grey vertical line. Indeed, for simplicity, we assumed a $\beta_{\text {thr }}$ nominal value of $4 \times 10^{-7} \mathrm{~m}^{-1} \mathrm{sr}^{-1}$ for all the case studies discussed in Sect. 5 below, unless indicated otherwise (we leave the discussion of the effects of this choice to those case studies). The clustering of the fine mode $\beta_{\text {thr }}$ ranges, along with the 9 March 2011 illustration of the previous section, suggests in a general sense, that $\tau_{\mathrm{f}}^{\prime}$ as well as $\tau_{\mathrm{f}}$ can, in spite of the typically stronger variability associated with $\tau_{\mathrm{c}}^{\prime}$ and $\tau_{\mathrm{c}}$, be justifiably associated with the presence of fine mode aerosols in the atmosphere. Those $\beta_{\text {thr }}$ ranges associated with $\left\langle\tau_{\mathrm{c}}^{\prime}\right\rangle-\left\langle\tau_{\mathrm{c}}\right\rangle$ and $\left\langle\tau_{\mathrm{a}}^{\prime}\right\rangle-\left\langle\tau_{\mathrm{a}}\right\rangle$ values that are large merely reflect a situation where $\left\langle\tau_{\mathrm{c}}^{\prime}\right\rangle$ and $\left\langle\tau_{\mathrm{a}}^{\prime}\right\rangle$ change little with $\beta_{\mathrm{thr}}$ (the cloud/aerosol classification changes little with $\left.\beta_{\text {thr }}\right)$.

The bottom graph of Fig. 3b shows the uncertainty in $\beta_{\text {thr }}$ given a requirement that $R_{x}^{2}$ be greater than 0.19 . The threshold of 0.19 was selected in an attempt to broadly quantify a $\beta_{\text {thr }}$ range of significant $R_{x}^{2}$ values for all events: it represents a cutoff whose probability distribution was significantly different from zero for all events of the study ${ }^{4}$. One can observe that the positions of the $R_{\mathrm{f}}^{2}$ ranges are also clustered near the $\beta_{\text {thr }}$ value of $4 \times 10^{-7} \mathrm{~m}^{-1} \mathrm{sr}^{-1}$. The notable exceptions to this observation are isolated points of higher $R_{\mathrm{f}}^{2}$ values for 14 March 2012. The former (large $\beta_{\mathrm{thr}}$ ) case represents a region where $\tau_{\mathrm{c}}^{\prime}$ is negligible and thus where $\tau_{\mathrm{f}}^{\prime}$ is characterized by $R_{\mathrm{f}}^{2}$ values that are strongly influenced by coarse mode variance (when $\tau_{\mathrm{c}}$ is not negligible and there is every

\footnotetext{
${ }^{4}$ More precisely, the lower uncertainty of Fisher's $Z$ transformation $\left(Z_{x}=\ln \left[\left(1+R_{x}\right) /\left[\left(1-R_{x}\right)\right]\right]\right)$ was greater than zero at a $95 \%$ confidence level (Fisher's $Z$ transformation is, for example, presented in Spiegel, 1961)
}

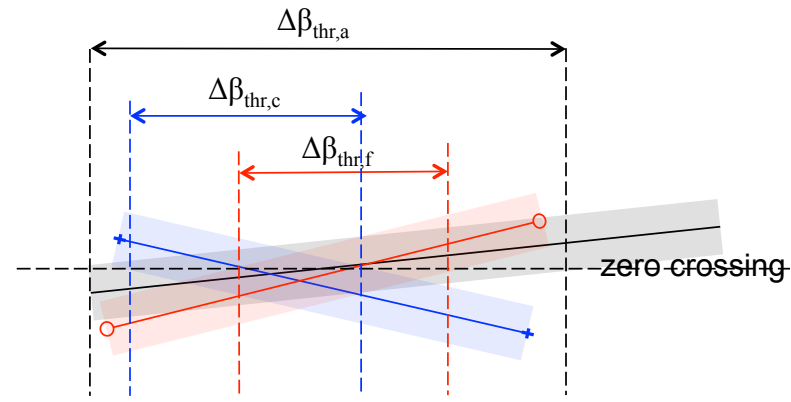

a.

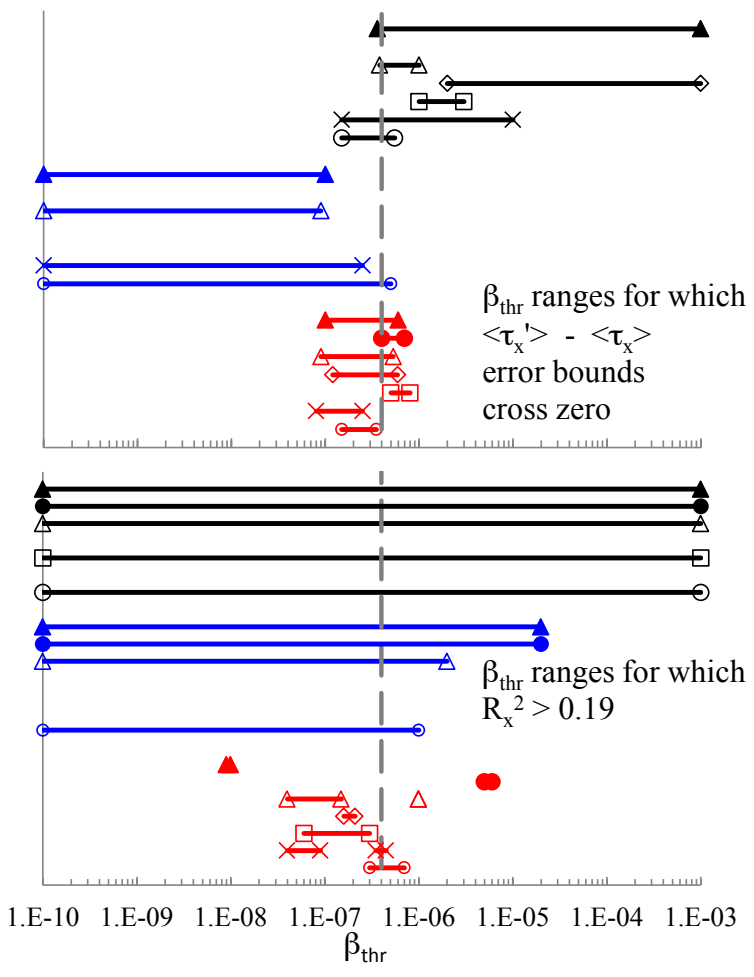

b.

Figure 3. (a) $\beta_{\text {thr }}$ ranges (dashed vertical lines) where bands of $\left\langle\tau_{\mathrm{f}}^{\prime}\right\rangle-\left\langle\tau_{\mathrm{f}}\right\rangle,\left\langle\tau_{\mathrm{c}}^{\prime}\right\rangle-\left\langle\tau_{\mathrm{c}}\right\rangle$ and $\left\langle\tau_{\mathrm{a}}^{\prime}\right\rangle-\left\langle\tau_{\mathrm{a}}\right\rangle$ cross the zero line (horizontal dashed line) for an optical depth error represented by the semitransparent bands of red, blue and grey respectively. The diagram is meant to be a conceptual representation of the how error bar banding would be applied to real data such as the middle graph of Fig. 2a. (b) Derived $\beta_{\text {thr }}$ ranges for all events (with red, blue and black representing, as always, the fine, coarse and total components). The top graph shows ranges for an assumed optical depth error of $0.03\left(\Delta \beta_{\text {thr }}\right.$ as per $\left.\mathbf{a}\right)$, while the bottom graph shows ranges for $R_{x}^{2}>0.19$. The end symbols of each horizontal segment: ॰, X, $\square, \diamond, \Delta, \bullet$ and $\boldsymbol{\Delta}$ represent, respectively, the event dates of 9 and 10 March and 21 February 2011 and 13, 14, 15 March as well as the combination of 13-15 March 2012. The grey, dashed vertical line indicates, the nominal value of $\beta_{\mathrm{thr}}=4 \times 10^{-7} \mathrm{~m}^{-1} \mathrm{sr}^{-1}$ chosen for the event analyses of Sect. 5 . 
evidence in the behavior of the backscatter profile that $\tau_{\mathrm{c}}^{\prime}$ is artificially low). In the latter (small $\beta_{\mathrm{thr}}$ ) case, $\tau_{\mathrm{f}}^{\prime}$ is negligible at such a small value of $\beta_{\mathrm{thr}}$, and so the correlation with $\tau_{\mathrm{f}}$ is optically insignificant (it depends on relatively few, generally noisy samples of $\beta$ ). Finally, the reasons for the broad $\beta_{\text {thr }}$ ranges for $R_{\mathrm{c}}^{2}$ and $R_{\mathrm{a}}^{2}$ have already been discussed in the analysis of the 9 March 2011 illustration above.

\subsubsection{Lidar optical depth errors}

The most significant source of lidar optical depth error in terms of the discrimination into aerosol and cloud components is arguably the sensitivity of $\tau_{\mathrm{f}}^{\prime}, \tau_{\mathrm{c}}^{\prime}$ and $\tau_{\mathrm{a}}^{\prime}$ to $\beta_{\mathrm{thr}}$ described in the previous section. One can also question the rigor of our simplistic aerosol/cloud discrimination algorithm. However, rather than attempt to seek out an ostensibly better algorithm using such indicators as the color ratio of two elastic lidar bands, spatial/time derivatives of $\beta$ etc., we elected to retain the processing and ease of interpretation advantages afforded by this standard approach while appealing to the empirical results of Sect. 5 to justify its choice (in general, we leave the details related to errors in lidar and star photometer optical depths to the event based analysis of Sect. 5).

The consequence of using prescribed lidar ratios $\left(S_{\mathrm{f}}\right.$ and $S_{\mathrm{c}}$ ) for the aerosol and cloud components does merit some particular reflection because it is readily generalized. An easy-to-demonstrate consequence of our simplistic aerosol/cloud discrimination algorithm is that changes in $S_{\mathrm{f}}$ and $S_{\mathrm{c}}$ will not affect the fine and coarse mode plots of $R_{x}^{2}$ vs. $\beta_{\mathrm{thr}}$. They will, however, shift the fine, coarse and total AODs, up or down, by simple multiplicative factors $\left(\left[S_{\mathrm{f}} / S_{\mathrm{f}, 0}\right] \tau_{\mathrm{f}, 0}^{\prime},\left[S_{\mathrm{c}} / S_{\mathrm{f}, 0}\right] \tau_{\mathrm{c}, 0}^{\prime}\right.$ and $\left[S_{\mathrm{f}} / S_{\mathrm{f}, 0}\right] \tau_{\mathrm{f}, 0}^{\prime}+\left[S_{\mathrm{c}} / S_{\mathrm{f}, 0}\right] \tau_{\mathrm{c}, 0}^{\prime} \mathrm{re}-$ spectively for an initial set of prescribed values indicated by the subscript " 0 "). This will have a proportionate effect on the $\left\langle\tau_{x}^{\prime}\right\rangle$ as well as the $\left\langle\tau_{x}^{\prime}\right\rangle-\left\langle\tau_{x}\right\rangle$ vs. $\beta_{\text {thr }}$ curves and, shift the zero crossing position on the $\beta_{\text {thr }}$ axis by a factor that is readily computed for all events (from the multiplicative factors and from empirically derived slopes of $\left.\operatorname{dlog} \beta_{\mathrm{thr}} / \mathrm{d}\left\langle\tau_{x}^{\prime}\right\rangle\right)$. For the fine mode case this yields changes in $\log \beta_{\mathrm{thr}}<\sim 0.2$ for relative changes in $S_{\mathrm{f}}$ of $20 \%$ (verified for all our analyzed events). This change will, for example, not substantially effect the relatively small fine mode $\beta_{\text {thr }}$ ranges observable in Fig. 3b.

\section{Event analysis}

In this section we present a process-level analysis of several events detected at Eureka during the polar winters of 2010-2011 and 2011-2012. With the exception of Sect. 5.5, star photometry data were not cloud screened because of the objective to include in our analysis the dynamics of AOD variations in coarse mode dominant events. The latter would be affected by the cloud-screening algorithm. Unless other-

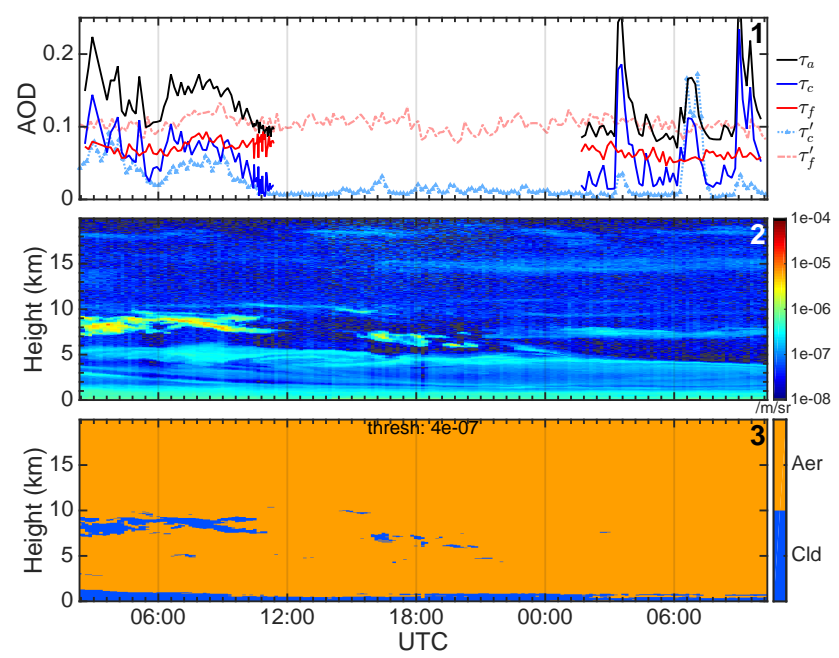

Figure 4. Eureka aerosol event, 9-10 March 2011. For a description of each pane, see the caption of Fig. $2 b$.
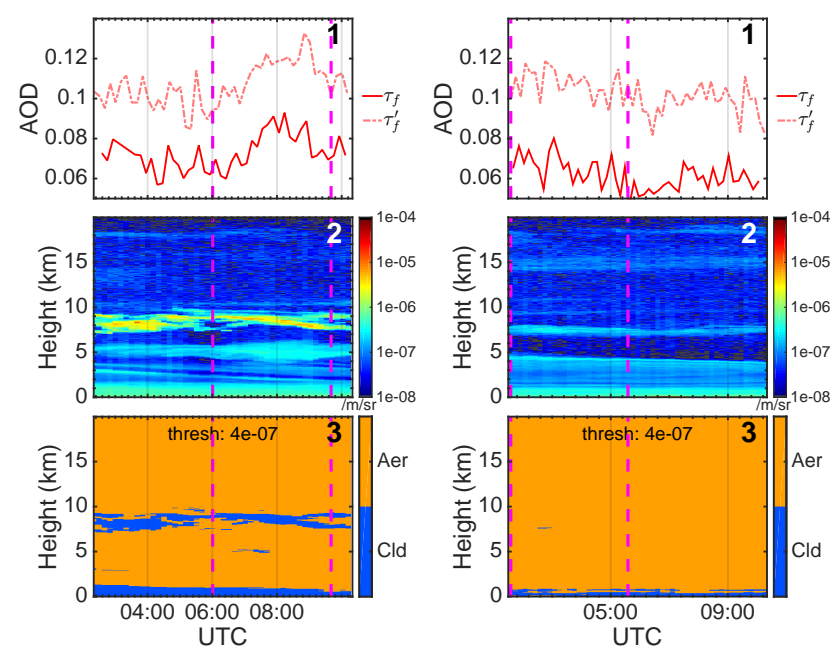

Figure 5. Zoom of the backscatter profile and the fine mode optical depths ( $\tau_{\mathrm{f}}^{\prime}$ and $\tau_{\mathrm{f}}$ ) as a function of time on 9 March 2011 (left) and 10 March 2011 (right). The 9 March case is the $\beta_{\mathrm{thr}}=$ $4 \times 10^{-7} \mathrm{~m}^{-1} \mathrm{sr}^{-1}$ (right hand) case of Fig. 2a with a focus on fine mode optical depth variation. The purple dashed vertical lines show the approximate limits of where the plume (between 4 and $6 \mathrm{~km}$ on 9 March and at around $8 \mathrm{~km}$ on 10 March) is at its most optically active. Same pane description as in Fig. 2b.

wise noted, all star photometry AODs are reported at $500 \mathrm{~nm}$, while the CRL backscatter signal refers to the $532 \mathrm{~nm}$ channel. All time values are given in UTC.

\subsection{Short-term aerosol events (9-10 March 2011)}

Figure 4 shows star photometry and lidar data obtained at Eureka between 00:00 on 9 March and 13:00 on 10 March 2011. Considerable atmospheric complexity during the given time period is manifested by the presence of what we interpret to 
be several distinct features: aerosol layers up to $6 \mathrm{~km}$, tropospheric clouds between 6 and $10 \mathrm{~km}$ as well as optically weak polar stratospheric cloud (PSC) layers above $14 \mathrm{~km}$. In addition, 10 March is associated with surface-layer ice crystals in the lowest $500 \mathrm{~m}$ (discussed in more detail below). The $\left\langle\tau_{\mathrm{f}}\right\rangle$ value of approximately 0.06 , across the total period, is generally dominated by the low amplitude backscatter aerosol layers between 1 and $6 \mathrm{~km}$. Aerosol plumes were especially prominent on 9 March, gradually thinning out towards the end of the 2-day period. We see that, in general, $\tau_{\mathrm{f}}^{\prime}$ overestimates $\tau_{\mathrm{f}}$ by an average difference $\sim 0.03$. Focusing on the fine mode variation and shorter term scales during both 9 and 10 March (Fig. 5), the best correlation between $\tau_{\mathrm{f}}^{\prime}$ and $\tau_{\mathrm{f}}$ is achieved on 9 March (left side of Fig. 5) with an $R_{\mathrm{f}}^{2}$ value of 0.61 . On both days, we ignored high frequency AOD variations after approximately 10:25, inasmuch as the measurements beyond that time were influenced by the background scattering signal associated with the rising sun. For 10 March, the degree of correlation between $\tau_{\mathrm{f}}^{\prime}$ and $\tau_{\mathrm{f}}$ is marginal at best ( $R_{\mathrm{f}}^{2}$ value of 0.18 ), but the temporal variation in both $\tau_{f}$ and $\tau_{\mathrm{f}}^{\prime}$ is weak to begin with. We would argue nonetheless, that both $\tau_{\mathrm{f}}^{\prime}$ and $\tau_{\mathrm{f}}$ react (with a precision $\lesssim 0.01$ ) on both days to the most optically active ${ }^{5}$ portion of the (presumed) fine mode layer between a few hundred meters above ground-level to between around $6 \mathrm{~km}$ on 9 March to $8 \mathrm{~km}$ on 10 March (the most optically active regions being between the dashed purple lines of Fig. 5). It should be pointed that the 10 March $R_{\mathrm{f}}^{2}$ vs. $\beta_{\text {thr }}$ curve shows a second, marginally significant peak around $5 \times 10^{-8} \mathrm{~m}^{-1} \mathrm{sr}^{-1}$ in addition to the peak around $4 \times 10^{-7} \mathrm{~m}^{-1} \mathrm{sr}^{-1}$ (cf. Fig. 3b). The smaller $\beta_{\mathrm{thr}}$ value represents a $\beta_{\text {thr }}$ region where $\tau_{\mathrm{f}}^{\prime}$ is roughly constant across that time period (virtually all the plume structure seen on Fig. 5 has been assigned to the cloud class) and the resulting $\tau_{\mathrm{f}}^{\prime}$ variation is $<\sim 0.003$. This means that any correlation between $\tau_{\mathrm{f}}^{\prime}$ and $\tau_{\mathrm{f}}$ is likely influenced, if not dominated by non-physical perturbations of $\tau_{\mathrm{f}}^{\prime}$.

Both examples of Fig. 5 appear to show an appreciable sensitivity to quite small changes in fine mode aerosol optical depth as well as a temporal coherence between passive and active measurements which is rarely if ever reported in the literature. We note that the PSCs at around $14 \mathrm{~km}$ (see also Fig. 4 for a more general context) are characterized by optical depths that are significantly less than the tropospheric optical depths and are a minor influence on this analysis.

Returning to Fig. 4, one can observe that $\tau_{\mathrm{c}}^{\prime}$ corresponds moderately well with $\tau_{\mathrm{c}}$, especially for the cloud feature in the first half of 9 March (the RMS difference between $\tau_{\mathrm{c}}^{\prime}$ and $\tau_{\mathrm{c}}$ is 0.04 for the whole period, and 0.03 for $9 \mathrm{March}$ ). Of particular interest are the three coarse mode peaks on 10 March that are evident in both star photometry and lidar data. The

\footnotetext{
5"Optically active" refers to significant increases in AOD and backscatter coefficient in star photometry and lidar data, respectively.
}

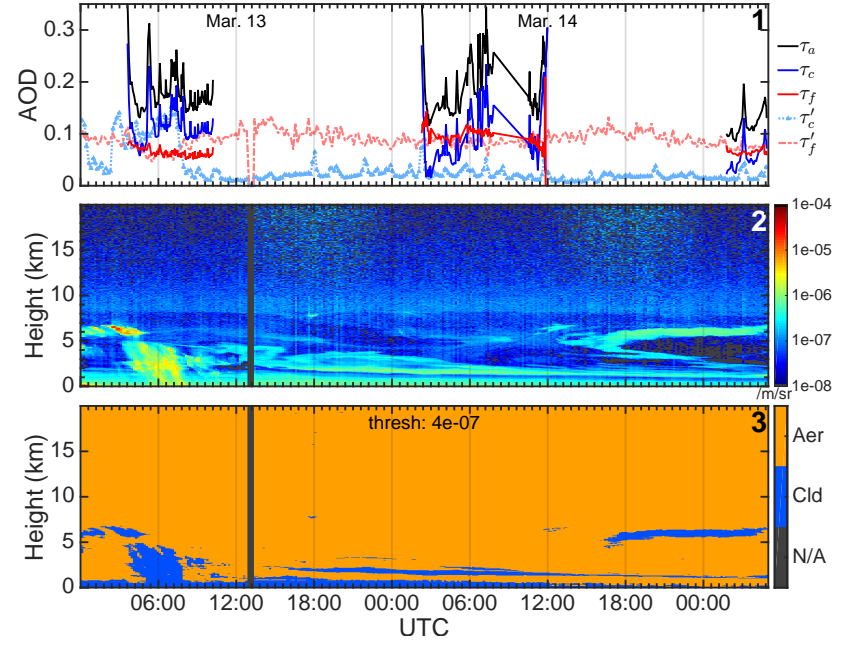

Figure 6. Same pane description as Fig. 2b but for 1315 March 2012.

signal enhancements are due to surface-layer ice crystals and are discussed in more detail in Sect. 5.3.

All of these indicators would tend to confirm our original hypothesis that both $\tau_{\mathrm{f}}^{\prime}$ and $\tau_{\mathrm{c}}^{\prime}$ can be approximately derived from the $\beta_{\mathrm{thr}}$ classification paradigm and that the estimates are approximately coherent with $\tau_{\mathrm{f}}$ and $\tau_{\mathrm{c}}$ respectively. The errors in lidar AODs inherent in such a comparison include the errors associated with the classification criteria, the assigned lidar ratio values $(\approx 10-20 \mathrm{sr}$ or hence $<\sim 20-40 \%$ error in predicted $\tau_{\mathrm{f}}^{\prime}$ or $\tau_{\mathrm{c}}^{\prime}$ values), and artifacts such as the vertical streaks (banding) observable in pane 2 of Fig. 5 (which we estimate to $<\sim 0.01$ in those figures). Those vertical-streak artifacts are due to a low number of photon counts in the normalization (molecular) region, which makes it difficult to measure the backscatter coefficient in this region accurately. The low number of photon counts is the high-altitude (near-tropopause) consequence of requiring a range of minimal aerosol contamination in the backscatter profile. This error in the normalization region will propagate downward in the lidar profile. The star photometer errors include the estimated AOD calibration errors $(\approx 0.03)$ and SDA errors $(\approx 10 \%)$.

\subsection{Multi-night aerosol event (13-15 March 2012)}

Figure 6 shows, what we suspect to be a multi-night event (low frequency, $\tau_{\mathrm{f}}^{\prime}$ and $\tau_{\mathrm{f}}$ variation across the three nights with mild peaking on 14 March) as well as an illustration of the difficulties one encounters in attempting to identify low frequency and low amplitude fine mode events when there is relatively little temporal variation associated with the fine mode optical depth. The mixture of aerosol and cloud on 13 March is particularly fraught with difficulties in that the $\tau_{\mathrm{c}}^{\prime}$ and $\tau_{\mathrm{c}}$ signals tend to dominate their fine mode analogues earlier in the night, while the $\tau_{\mathrm{c}}^{\prime}$ vs. $\tau_{\mathrm{c}}$ as well as $\tau_{\mathrm{f}}^{\prime}$ 
vs. $\tau_{\mathrm{f}}$ results tend to diverge in the latter part of the night. We found, as part of our $\beta_{\text {thr }}$ sensitivity study (applied to the entire three-night period), that the latter part of 13 March was a highly sensitive classification period since classification results changed rapidly with small changes in $\beta_{\text {thr }}$ (due to the presence of what was likely a mixture of heterogeneous thin cloud and fine mode aerosols). The result was that our $R_{\mathrm{f}}^{2}$ vs. $\beta_{\text {thr }}$ plot showed a sharp maximum similar to the bottom graph of Fig. 2b, but where the peak was only marginal (as per the $R_{\mathrm{f}}^{2}$ criterion of Fig. 3b) and below the range of acceptable $\left\langle\tau_{\mathrm{f}}^{\prime}\right\rangle-\left\langle\tau_{\mathrm{f}}\right\rangle$ differences (Fig. 3b). Thus, while the $R_{\mathrm{f}}^{2}$ peak suggests that this might well be a multi-night event, the actual $\left\langle\tau_{\mathrm{f}}^{\prime}\right\rangle-\left\langle\tau_{\mathrm{f}}\right\rangle$ range seems to indicate an inconsistency in our criteria. If one argues in favor of the robustness of the $R_{\mathrm{f}}^{2}$ criteria (in favor of a multi-night event), then we would have to appeal to such factors as $\tau_{\mathrm{f}}$ retrieval errors or the possibility that a simple binary cloud classification (cloud aerosol/separation) algorithm is, at least in this case, too simplistic.

\subsection{Low altitude ice crystals (10 March 2011)}

The proper detection of $\tau_{\mathrm{c}}$, whether it represents coarse mode aerosols or cloud, is an important test of the performance of the SDA (which is strongly dependent on the spectral curvature fidelity of the star photometer optical depths) and of the performance of any cloud screening algorithm. Figure 7 shows an extract of Fig. 4 for 10 March 2011 with the lidar data in panes 2 and 3 displayed only for the lowest $2 \mathrm{~km}$. The peaks in star photometry AODs at 03:25, 06:35 and 09:00 have a clear association in time with the obvious increase in backscatter coefficient in the lowest $250 \mathrm{~m}$. Furthermore, the SDA indicates that the observed features are coarse mode $\left(\tau_{\mathrm{c}}\right)$ dominant. While some weak fine mode backscatter layers are present at the higher altitudes (the relatively strong tropospheric and weaker stratospheric features of pane 2 in Fig. 4), $\tau_{\mathrm{c}}^{\prime}$ is clearly dominated by the low-altitude features. For the most extreme vertical profiles between 06:00 and 08:00, the first $250 \mathrm{~m}$ can contribute more than $80 \%$ to the column integrated $\tau_{\mathrm{c}}^{\prime}$ value (and more than $60 \%$ to the column integrated $\tau_{\mathrm{a}}^{\prime}$ ). The positions of the peaks in $\tau_{\mathrm{c}}^{\prime}$ correspond well in time to those of $\tau_{\mathrm{c}}$; the $\tau_{\mathrm{c}}^{\prime}$ values at the $\tau_{\mathrm{c}}$ peak times of 03:25 and 09:00, however, are significantly lower than the corresponding $\tau_{c}$ values. At these low altitudes the laser beam is not entirely within the field of view of the detection optics, so it is likely that the inconsistencies between $\tau_{\mathrm{c}}^{\prime}$ and $\tau_{c}$ are, at least in part, related to an incomplete overlap correction. However this correction is a crude approximation whose uncertainty increases with the proximity to the ground. It fails to explain why $\tau_{\mathrm{c}}^{\prime}>\tau_{\mathrm{c}}$ about the 06:35 peak and one must therefore appeal to additional factors to explain the discrepancy (SDA retrieval errors, errors in cloud/aerosol classification, etc.). In the case of overlap function problems, star photometry measurements become particularly relevant given inherent lidar difficulties at the lowest altitudes.

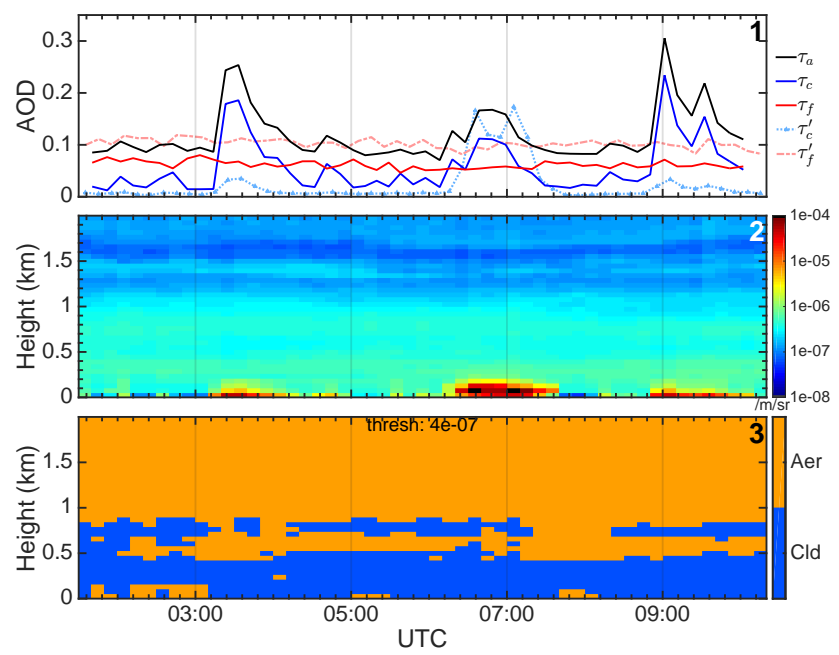

Figure 7. An altitude and temporal zoom of Fig. 4 for 10 March 2011. The CRL profiles are shown for the lowest $2 \mathrm{~km}$.

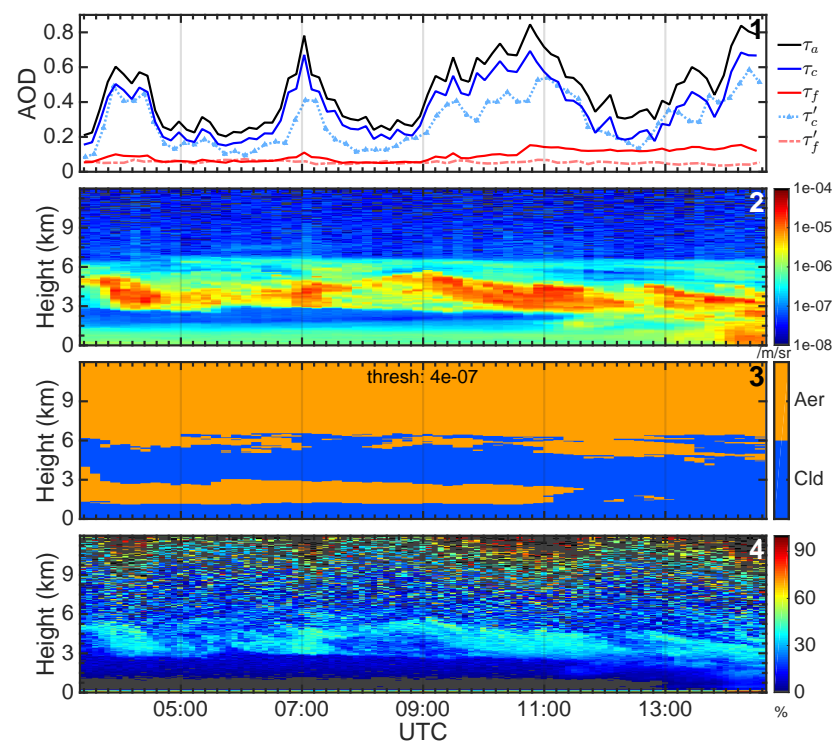

Figure 8. Thin cloud event of 21 February 2011. The description of the top 3 panes is identical to the description given in Fig. 4. Pane 4 is the CRL linear depolarization ratio (\%). The depolarization ratio data were not corrected for overlap in the bottom-most $1 \mathrm{~km}$.

\subsection{Mid-tropospheric thin clouds (21 February 2011)}

Generally, clouds are relatively opaque and strongly attenuate the inherently weak star radiation. Some types of clouds (such as thin ice clouds, TICs), however, can be optically thin, while extending vertically for several kilometers. An example of such a cloud event was observed on 21 February 2011 at Eureka is shown in Fig. 8 (some aspects of this event were originally discussed in Ivanescu et al., 2011).

The optical depth values of pane 1 show a significant variation between 0.2 and 0.8 during the 11.5 -h measurement pe- 
riod. The SDA applied to the star photometry data set shows the dominance of the coarse mode particles which compose the cloud. The assumption that the coarse mode optical depth variation can be ascribed to clouds is supported by the CRL data showing strong backscatter coefficient features in the $3-5 \mathrm{~km}$ altitude range. Perhaps more convincingly, the presence of clouds is confirmed by the high depolarization ratio values $^{6}$ (up to $40-50 \%$, pane 4 ), which are spatially correlated with the high backscatter coefficient values of pane 2 . Such high depolarization ratio values are typical of ice crystal clouds. The CRL integrated signal associated with cloud features, $\tau_{\mathrm{c}}^{\prime}$, shows good correlation $\left(R^{2}=0.78\right)$ with the star photometry coarse mode $\left(\tau_{\mathrm{c}}\right) . \tau_{\mathrm{c}}^{\prime}$ is nevertheless, somewhat smaller than $\tau_{\mathrm{c}}$ beyond 05:00. The difference can, at least in part, be due to the prescribed generic lidar ratio of $20 \mathrm{sr}$ for the clouds. A slightly higher value of $S_{\mathrm{a}}=25 \mathrm{sr}$ might be more appropriate as it would result in better agreement between $\tau_{\mathrm{c}}^{\prime}$ and $\tau_{\mathrm{c}}$ (we would also note that the overlap function at the relatively high-altitude positions of the clouds is not an issue). The reader will further note that both $\tau_{\mathrm{f}}^{\prime}$ and $\tau_{\mathrm{f}}$ are relatively stable with realistic values in spite of being dominated by the coarse mode contributions. The $\tau_{\mathrm{f}}$ values are around 0.07 until 09:00 and agree closely with those of $\tau_{\mathrm{f}}^{\prime}$. Beyond 09:00 $\tau_{\mathrm{f}}$ rises to the mean value of 0.12 , but $\tau_{\mathrm{f}}^{\prime}$ does not undergo a similar change. This discrepancy might, for example, be associated with the SDA uncertainties, given the predominantly coarse mode scene and/or errors in the aerosol/cloud classification scheme employed to retrieve $\tau_{\mathrm{c}}^{\prime}$ (in the latter case, the apparent stability of $\tau_{\mathrm{f}}^{\prime}$ seen in Fig. 8, after around 10:00, could, in actual fact, be a failure of the classification algorithm to respond to an increased presence of fine mode particles).

\subsection{Example of cloud screening}

We examined the performance of temporal cloud screening for several case studies and present one of the more instructive cases in this section. Figure 9 shows the results of applying the temporal filters of Table 3 to the AOD time series on the 10 March 2011 low-altitude crystal event of Fig. 7 (filter 1, the optical depth upper limit condition, is not applicable to this case since all AODs are smaller than 0.35).

As established in Sect. 5.3, the AOD peaks centered at 03:25, 06:35 and 09:00 are due to surface layer ice crystals in the lowest $500 \mathrm{~m}$. Our goal was to evaluate the performance of the temporal cloud screening (and effectively extend the definition of "cloud" to include these low lying ice crystals). Pane 1 shows points that were classified by the cloud filters as cloud contaminated by abrupt high-frequency temporal variations (the green "CldScr" circles). For this date, the filters appeared to perform relatively well in flagging the optical depths associated with the coarse mode peaks $\left(\tau_{\mathrm{c}}^{\prime}\right.$ of

\footnotetext{
${ }^{6}$ Depolarization ratio data for 2011 was generally noisy due to technical difficulties; in this case, however, a strong signal stood out above the noise.
}

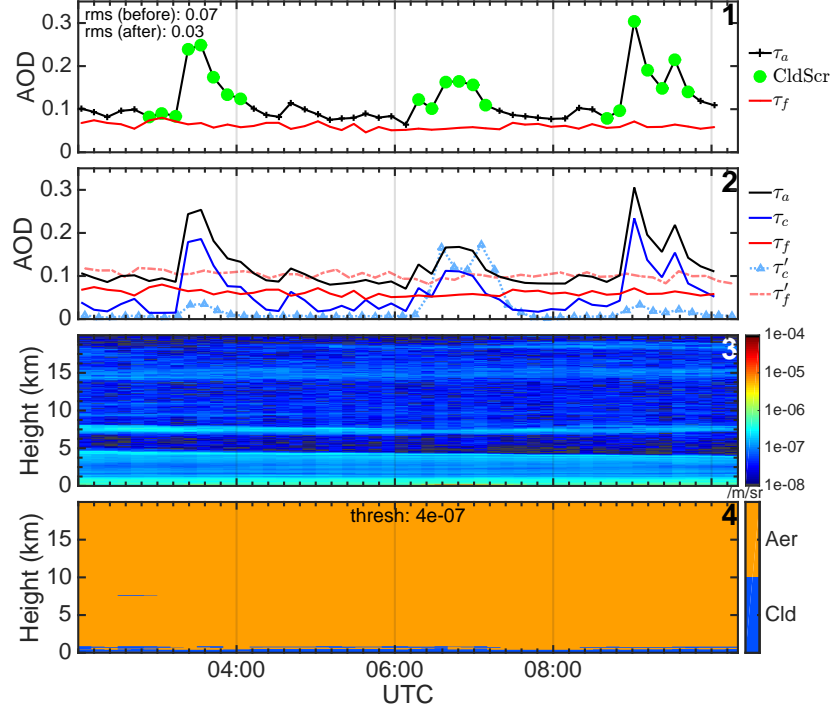

Figure 9. Cloud-screening illustration for the 10 March 2011 lowaltitude ice crystal event. Pane 1: cloud points (green circles) that would be eliminated based on a temporal cloud-screening algorithm (see text for details); fine mode star photometry AOD $(500 \mathrm{~nm})$ is reproduced for ease of comparison. The description of panes 2-4 is as in Fig. 2b.

pane 2). The remaining points of the black AOD curve of pane 1 (which in principle are associated only with aerosol signal) should be comparable to the fine mode red curve of pane 2 (which is reproduced in pane 1 for ease of comparison); the RMS difference between the two improved from 0.07 to 0.03 without and with cloud filtering. One could go a step further and argue that the systematically greater AODs, after cloud screening, contain a small OD contribution due to spatially homogeneous coarse mode aerosols and/or spatially homogeneous clouds that the temporal cloud screening algorithm failed to eliminate. This argument is rendered more believable because, outside the three peaks of Fig. 9, the amplitude of $\tau_{\mathrm{c}} \sim\left(\tau_{\mathrm{a}}\right.$ (cloud screened) $\left.-\tau_{\mathrm{f}}\right)$. However, one could equally well question the accuracy of the SDA fine mode retrieval which becomes less accurate for small AODs (O'Neill et al., 2003).

\section{Summary and conclusions}

In this paper, we presented recent progress related to the nighttime optical depth retrievals of aerosols and clouds using star photometry at the high Arctic PEARL station. Optical measurements, and specifically AOD measurements, acquired during the polar winter are scarce compared to the ensemble of polar summer measurements but nonetheless represent an important source of information for the development of aerosol optical climatologies, instrumental intercomparisons, satellite validation (such as CALIOP) and tie-down points for aerosol/cloud models. In the spring of 2011 and 
2012, the SPSTAR star photometer was operating whenever possible, acquiring AOD measurements in tandem with the acquisition of vertical profiles from the CRL Raman lidar.

Star photometry is a relatively new technology that is subject to weak-signal problems exacerbated in the extreme Arctic conditions. The accuracy of the derived AODs ultimately depends on the quality of derived calibration values and other instrumental and environmental factors such as optics degradation or background field characterization. Given the slowly changing optical air mass values characteristic of most measurement stars, Langley calibration is problematic in the Arctic. The SPSTAR was calibrated using differential two-star measurements. Only points satisfying cloud filtering and measurement uncertainty criteria were considered for calibration. The quality of the calibration values $(C)$ was confirmed by studying their evolution throughout the entire measurement period. The AOD errors due to the spread in the potential calibration values were estimated to be 0.025 . The total error in AOD, $\delta\left(\tau_{\text {aer }}\right)$, was estimated to be $\delta\left(\tau_{\text {aer }}\right) \lesssim 0.03$ for an optical air mass of 1 . We note that it would be, as indicated by Eq. (A7), half this value for an air mass of 2 (we purposefully avoided this aspect in the text above because the optical air mass influence on optical depth error is subject to at least two conflicting factors: the beneficial increase in lineof-site optical depth as it increases from small values and the increase in line-of-site optical inhomogeneities, at lower elevation angles).

Short timescale $(\sim$ minutes $)$ process-level analysis of aerosol and cloud events simultaneously captured in photometric and lidar data are essential to ensure that extracted extensive (bulk) and intensive (per particle) optical and microphysical indicators are coherent and physically consistent. This type of analysis is rarely addressed in the literature and we have found no measurement series that deal with process-level analysis of polar winter data sets. Using the star photometry-lidar synergy we have detected and characterized several distinct events throughout the measurement periods. In particular, we provided case studies of the following: aerosols (short term aerosol events on 9 and 10 March 2011, a potential multi-night aerosol event across three polar nights (13-15 March 2012), ice crystals (10 March 2011) and thin clouds (21 February 2011). For this analysis, we employed prescribed values of extinction to backscatter ratio (lidar ratio) values and applied these values to a simple threshold based classification of the lidar backscatter coefficient images. In general, the results were encouraging in terms of the physical coherence between fine and coarse mode star photometry ODs $\left(\tau_{\mathrm{f}}\right.$ and $\tau_{\mathrm{c}}$ ) and corresponding lidar optical depths of aerosol and cloud layers $\left(\tau_{\mathrm{f}}^{\prime}\right.$ and $\left.\tau_{\mathrm{c}}^{\prime}\right)$. The best correlation between $\tau_{\mathrm{f}}$ and $\tau_{\mathrm{f}}^{\prime}$ was achieved for an aerosol event on 9 March with an $R^{2}$ (coefficient of determination) value of 0.61 , while the measurements during the thin cloud event observed on 21 February 2011 showed the best correlation between $\tau_{\mathrm{c}}^{\prime}$ and $\tau_{\mathrm{c}}^{\prime}\left(R^{2}=0.78\right)$. We also argued that $R^{2}$ was the most robust means of comparing lidar and star photometer data since it was sensitive to significant optico-physical variations associated with these two independent data sources while being minimally dependent on retrieval and calibration artifacts. Differences between $\tau_{\mathrm{f}}^{\prime}$ and $\tau_{\mathrm{f}}$ as well as between $\tau_{\mathrm{c}}^{\prime}$ and $\tau_{\mathrm{c}}$ are clearly also useful but are dependent on such artifacts.

Studying seasonal aerosol trends necessitates cloudscreening procedures. We have adapted a cloud-screening algorithm for star photometry applications to help detect cloudcontaminated optical depths based on high-frequency optical depth variations. In addition, we used SDA-retrieved fine mode AOD as a means of performing de facto spectral cloud screening and accordingly, as a means of verifying the quality of temporal cloud screening. In general, a combination of temporal filters performs well for most cloud features with cloud-screened optical depths (AOD) being in adequate agreement with spectrally cloud-screened optical depths $\left(\tau_{\mathrm{f}}\right)$. Temporal cloud screening, nevertheless, predictably fails for low-frequency variations associated with ice crystals or homogeneous clouds. In this case, spectral cloud screening has a distinct advantage of not being dependent on the limitations of employing temporal variations as a means of identifying clouds. An illustration was given where the overestimate of temporally cloud-screened AODs relative to SDAderived fine mode AODs could be attributed to spatially homogeneous clouds and/or coarse mode aerosols

We conclude by saying that the synergism employed in the present work enabled the assemblage of evidence for events whose process-level understanding will inevitably generate greater confidence in star photometer retrievals as well as star photometer/lidar comparisons and will lead to the improvement of critical statistics such as multi-year climatologies. Such an assemblage is non-trivial in a low AOD (low signal to noise) environment such as the Arctic. 


\section{A1 Estimated total error in $\tau_{\text {aer }}$}

The total AOD error is a function of the errors in all the component parameters employed in its retrieval. Expressing Eq. (3) in terms of numerical counts yields

$\mathrm{CN}=\mathrm{CN}_{0} e^{-m \tau}$,

where $\mathrm{CN}_{0}$ is the extraterrestrial numerical count value for a given star at a given wavelength. Differentiating this expression yields

$\mathrm{dCN}=e^{-m \tau} \mathrm{dCN}_{0}+\mathrm{CN}_{0}(-m \tau) e^{-m \tau}$,

$\frac{\mathrm{dCN}}{\mathrm{CN}}=\frac{\mathrm{dCN}_{0}}{\mathrm{CN}_{0}}-m \mathrm{~d} \tau$,

$\mathrm{d} \tau=\frac{1}{m} \frac{\mathrm{dCN}_{0}}{\mathrm{CN}_{0}}-\frac{1}{m} \frac{\mathrm{dCN}}{\mathrm{CN}}$.

Using Eq. (4) we can solve for the total error in the aerosol optical depth

$$
\begin{aligned}
\mathrm{d} \tau_{\text {aer }}= & \frac{1}{m} \frac{\mathrm{dCN}_{0}}{\mathrm{CN}_{0}}-\frac{1}{m} \frac{\mathrm{dCN}}{\mathrm{CN}} \\
& -\mathrm{d} \tau_{\text {ray }}-\mathrm{d} \tau_{\mathrm{O}_{3}}-\mathrm{d} \tau_{\mathrm{NO}_{2}}-\mathrm{d} \tau_{\mathrm{H}_{2} \mathrm{O}}-\text { etc. }
\end{aligned}
$$

We will, from this point on, assume that Rayleigh optical depths errors are negligible and that $\mathrm{H}_{2} \mathrm{O}$ optical depth errors are negligible in the UV and visible spectral regions. Assuming that all remaining errors are randomly distributed, an average over a large number of samples at a given solar air mass will yield the mean square sum;

$\left\langle\mathrm{d} \tau_{\text {aer }}\right\rangle=$

$\sqrt{\frac{1}{m}\left\langle\left(\frac{\mathrm{dCN}_{0}}{\mathrm{CN}_{0}}\right)^{2}\right\rangle+\frac{1}{m}\left\langle\left(\frac{\mathrm{dCN}}{\mathrm{CN}}\right)^{2}\right\rangle+\left\langle\left(\mathrm{d} \tau_{\mathrm{O}_{3}}\right)^{2}\right\rangle+\left\langle\left(\mathrm{d} \tau_{\mathrm{NO}_{2}}\right)^{2}\right\rangle}$.

We then approximate the differentials by their RMS difference relative to their true value and the denominators by their mean to obtain

$\delta\left(\tau_{\text {aer }}\right)=$

$\sqrt{\left(\frac{1}{m}\right)^{2}\left\{\left(\frac{\delta\left(\mathrm{CN}_{0}\right)}{\left\langle\mathrm{CN}_{0}\right\rangle}\right)^{2}+\left(\frac{\delta(\mathrm{CN})}{\langle\mathrm{CN}\rangle}\right)^{2}\right\}+\delta^{2}\left(\tau_{\mathrm{O}_{3}}\right)+\delta^{2}\left(\tau_{\mathrm{NO}_{2}}\right)+\delta^{2}\left(\tau_{\mathrm{H}_{2} \mathrm{O}}\right)}$.

In order to obtain an approximate estimate for $\delta\left(\tau_{\text {aer }}\right)$ we set $\frac{\delta\left(\mathrm{CN}_{0}\right)}{\left\langle\mathrm{CN}_{0}\right\rangle}=0.025$, (Sect. 4.2, for a link between the differential error in $C$ and $\mathrm{CN}_{0}$ see Sect. A2) $\delta(\mathrm{CN})=1$, a minimum value for $\langle\mathrm{CN}\rangle$ of $75, \delta\left(\tau_{\mathrm{O}_{3}}\right)=0.004$, and $\delta\left(\tau_{\mathrm{NO}_{2}}\right)=0.003$ (Sect. 4.3.1). This then yields a total estimated error of

$\delta\left(\tau_{\text {aer }}\right) \sim \sqrt{\left(\frac{1}{m}\right)^{2}\left\{(0.025)^{2}+\left(\frac{1}{75}\right)^{2}\right\}+0.004^{2}+0.003^{2}}$.
This yields OSM error estimates of $\delta\left(\tau_{\text {aer }}\right)$ of 0.03 for $m=1$ and $\left(\tau_{\text {aer }}\right)$.

\section{A2 AOD error in terms of the magnitude calibration constant $(C)$}

Equation (10), written in terms of irradiances is

$C=M_{0}^{*}-M_{0}=-2.5 \log \frac{F_{0}^{*}}{F_{0}}=-k \ln \frac{F_{0}^{*}}{F_{0}}=k \ln \frac{F_{0}}{F_{0}^{*}}$,

where the symbol $F$ represents an irradiance dependent quantity (i.e. digital counts, $\mathrm{CN}$, in the case of the star photometer) and $k=2.5 \times \log (e) \cong 1.086$. The above expression underscores that the constancy of $C$ (meaning it is only a function of the optics of the system) translates into a fixed star photometer-irradiance to star-catalog-irradiance transformation ratio, viz

$\frac{F_{0}}{F_{0}^{*}}=K, \quad$ where $C=k \ln K$.

Accordingly, a differential (error) in $C$ can be expressed as follows:

$\mathrm{d} C=k \mathrm{~d} \ln \frac{F_{0}}{F_{0}^{*}}=k\left(\frac{\mathrm{d} F_{0}}{F_{0}}-\frac{\mathrm{d} F_{0}^{*}}{F_{0}^{*}}\right)$.

If we assume that the error of the star catalog fluxes are relatively small then expression becomes

$\mathrm{d} C=k \frac{\mathrm{d} F_{0}}{F_{0}}$,

so that $\frac{\mathrm{d} F_{0}}{F_{0}}\left(\frac{\mathrm{dCN}}{\mathrm{CN}_{0}}\right)$ of Eq. (A6) can be evaluated as $\frac{\mathrm{d} C}{k}$ given a value of $\mathrm{d} C$. In terms of standard deviations, we can write

$\frac{\delta F_{0}}{\left\langle F_{0}\right\rangle}=\frac{\delta C}{k}$,

so that a value of $0.027 / 1.086=0.025$ can be substituted for $\frac{\mathrm{dCN}_{0}}{\mathrm{CN}_{0}}$ in Eq. (A8). 


\section{Appendix B}

Table B1. Symbol and acronym glossary.

\begin{tabular}{|c|c|}
\hline AOD & Aerosol Optical Depth (unitless) \\
\hline CRL & CANDAC Rayleigh-Mie-Raman lidar \\
\hline SDA & Spectral deconvolution algorithm \\
\hline$C$ & Star photometry calibration constant \\
\hline$M$ & Measured star magnitude on the ground \\
\hline$M_{0}$ & Derived extraterrestrial instrumental star magnitude \\
\hline$M_{0}^{*}$ & $\begin{array}{l}\text { Extraterrestrial star magnitude taken from the astronomical catalogue of Alekseeva } \\
\text { et al. (1996) }\end{array}$ \\
\hline$m$ & Optical air mass \\
\hline$\beta$ & $\begin{array}{l}\text { Backscattering coefficient (also known as the aerosol backscatter cross section) } \\
{\left[\mathrm{km}^{-1} \mathrm{sr}^{-1}\right]}\end{array}$ \\
\hline$\beta_{\mathrm{thr}}$ & $\begin{array}{l}\text { Threshold } \beta \text { value used to discriminate between clouds and aerosols. Unless other- } \\
\text { wise indicated, a nominal value of } 4 \times 10^{-7} \mathrm{~m}^{-1} \mathrm{sr}^{-1} \text { was used in the event analysis } \\
\text { of Sect. } 5\end{array}$ \\
\hline$S_{\mathrm{f}}, S_{\mathrm{c}}, S_{\mathrm{a}}$ & $\begin{array}{l}\text { lidar ratio (also known as the extinction to backscatter ratio) (sr) for fine mode, } \\
\text { coarse mode and total aerosol. Prescribed values of } 71 \text { and } 20 \mathrm{sr} \text { are employed for } \\
S_{\mathrm{f}} \text { and } S_{\mathrm{c}}\end{array}$ \\
\hline$\tau_{\mathrm{f}}, \tau_{\mathrm{c}}, \tau_{\mathrm{a}}$ & $\begin{array}{l}\text { fine mode, coarse mode and total aerosol optical depth derived from applying the } \\
\text { SDA algorithm to AOD spectra from the starphotometry }\end{array}$ \\
\hline$\tau_{\mathrm{f}}^{\prime}, \tau_{\mathrm{c}}^{\prime}, \tau_{\mathrm{a}}^{\prime}$ & $\begin{array}{l}\text { fine mode, coarse mode and total aerosol optical depth derived from integrating the } \\
\text { lidar profiles that have been partitioned into aerosol (assumed fine mode) and cloud } \\
\text { segments using the } \beta_{\text {thr }} \text { classification scheme }\end{array}$ \\
\hline
\end{tabular}


Acknowledgements. We would like to thank NSERC (National Sciences and Engineering Research Council), CFCAS (Canadian Foundation for Climate and Atmospheric Sciences), the Canadian Space Agency (CSA), CFI (Canadian Foundation for Innovation), the NSERC CREATE project (CREATE-AAS) and FRQNT (Fonds québécois de la recherche sur la nature et les technologies) for their financial support. The contributions of the CANDAC-PEARL operations team are gratefully acknowledged. We are thankful to Thomas Baader and his staff from Baader Planetarium GmbH: their AZ2000 alta-azimuth mount and the BAADER dome, facilitated important improvements in our star photometer measurement capabilities in the extreme polar winter environment of Eureka. We also appreciate the support of Matthew Martinsen and Shannon Coykendall while being on-site at Barrow. Finally, we would like to acknowledge the anonymous reviewers who provided many thoughtful and insightful comments.

Edited by: A. Sayer

\section{References}

Alados-Arboledas, L., Müller, D., Guerrero-Rascado, J. L., NavasGuzmán, F., Pérez-Ramírez, D., and Olmo, F. J.: Optical and microphysical properties of fresh biomass burning aerosol retrieved by Raman lidar, and star-and sun-photometry, Geophys. Res. Lett., 38, L01807, doi:10.1029/2010GL045999, 2011.

Alekseeva, G. A., Arkharov, A. A., Galkin, V. D., Hagen-Thorn, E. I., Nikanorova, I. N., Novikov, V. V., Novopashenny, V. B., Pakhomov, V. P., Ruban, E. V., and Shchegolev, D. E.: The Pulkovo spectrometric catalog of bright stars in the range from 320 to $1080 \mathrm{~nm}$, Balt. Astron., 5, 603-838, 1996.

Ansmann, A. and Müller, D.: Lidar and atmospheric aerosol particles, in: Lidar - Range-Resolved Optical Remote Sensing of the Atmosphere, edited by: Weitkamp, C., Springer Science + Business Media Inc., New York, 456 pp., 2005.

Ansmann, A., Wandinger, U., Riebesell, M., Weitkamp, C., and Michaelis, W.: Independent measurement of extinction and backscatter profiles in cirrus clouds by using a combined Raman elastic-backscatter lidar, Appl. Optics, 31, 7113, doi:10.1364/AO.31.007113, 1992.

ASDC: CALIPSO Quality Statements: Lidar Level 2 Cloud and Aerosol Profile Products Version Releases: 3.01, 3.02, distributed by Atmospheric Science Data Center, 2013.

Baibakov, K.: Characterization of Night-Time Aerosols Using Starphotometry, MSc thesis, University of Sherbrooke, 2009.

Barreto, A., Cuevas, E., Damiri, B., Guirado, C., Berkoff, T., Berjón, A. J., Hernández, Y., Almansa, F., and Gil, M.: A new method for nocturnal aerosol measurements with a lunar photometer prototype, Atmos. Meas. Tech., 6, 585-598, doi:10.5194/amt-6-585-2013, 2013.

Berkoff, T. A., Sorokin, M., Stone, T., Eck, T. F., Hoff, R., Welton, E., and Holben, B.: Nocturnal aerosol optical depth measurements with a small-aperture automated photometer using the moon as a light source, J. Atmos. Ocean. Tech., 28, 1297-1306, doi:10.1175/JTECH-D-10-05036.1, 2011.

Bradley, R. S., Keimig, F. T., and Diaz, H. F.: Climatology of surface-based inversions in the North American Arctic, J. Geo- phys. Res.-Atmos., 97, 15699-15712, doi:10.1029/92JD01451, 1992.

Brock, C. A., Cozic, J., Bahreini, R., Froyd, K. D., Middlebrook, A. M., McComiskey, A., Brioude, J., Cooper, O. R., Stohl, A., Aikin, K. C., de Gouw, J. A., Fahey, D. W., Ferrare, R. A., Gao, R.-S., Gore, W., Holloway, J. S., Hübler, G., Jefferson, A., Lack, D. A., Lance, S., Moore, R. H., Murphy, D. M., Nenes, A., Novelli, P. C., Nowak, J. B., Ogren, J. A., Peischl, J., Pierce, R. B., Pilewskie, P., Quinn, P. K., Ryerson, T. B., Schmidt, K. S., Schwarz, J. P., Sodemann, H., Spackman, J. R., Stark, H., Thomson, D. S., Thornberry, T., Veres, P., Watts, L. A., Warneke, C., and Wollny, A. G.: Characteristics, sources, and transport of aerosols measured in spring 2008 during the aerosol, radiation, and cloud processes affecting Arctic Climate (ARCPAC) Project, Atmos. Chem. Phys., 11, 2423-2453, doi:10.5194/acp-11-24232011, 2011.

Carswell, A. I.: Lidar measurements of the atmopshere, Can. J. Phys., 61, 378-395, 1983.

Curry, J. A., Meyer, F. G., Radke, L. F., Brock, C. A., and Ebert, E. E.: Occurrence and characteristics of lower tropospheric ice crystals in the arctic, Int. J. Climatol., 10, 749-764, doi:10.1002/joc.3370100708, 1990.

Curry, J. A., Hobbs, P. V., King, M. D., Randall, D. A., Minnis, P., Isaac, G. A., Pinto, J. O., Uttal, T., Bucholtz, A., Cripe, D. G., Gerber, H., Fairall, C. W., Garrett, T. J., Hudson, J., Intrieri, J. M., Jakob, C., Jensen, T., Lawson, P., Marcotte, D., Nguyen, L., Pilewskie, P., Rangno, A., Rogers, D. C., Strawbridge, K. B., Valero, F. P. J., Williams, A. G., and Wylie, D.: FIRE Arctic Clouds Experiment, B. Am. Meteorol. Soc., 81, 5-29, doi:10.1175/15200477(2000)081<0005:FACE>2.3.CO;2, 2000.

Duarte, C. M., Lenton, T. M., Wadhams, P., and Wassmann, P.: Abrupt climate change in the Arctic, Nat. Clim. Chang., 2, 6062, doi:10.1038/nclimate1386, 2012.

Eck, T. F., Holben, B. N., Reid, J. S., Dubovik, O., Smirnov, A., O'Neill, N. T., Slutsker, I., and Kinne, S.: Wavelength dependence of the optical depth of biomass burning, urban, and desert dust aerosols, J. Geophys. Res., 104, 31333-31349, doi:10.1029/1999JD900923, 1999.

Engvall, A.-C., Ström, J., Tunved, P., Krejci, R., Schlager, H., and Minikin, A.: The radiative effect of an aged, internally mixed Arctic aerosol originating from lower-latitude biomass burning, Tellus B, 61, 677-684, doi:10.3402/tellusb.v61i4.16864, 2009.

Frohlich, C. and Shaw, G. E.: New determination of Rayleigh scattering in the terrestrial atmosphere, Appl. Optics, 19, 1773-1775, 1980.

Herber, A., Thomason, L. W., Gernandt, H., Leiterer, U., Nagel, D., Schulz, K.-H., Kaptur, J., Albrecht, T., and Notholt, J.: Continuous day and night aerosol optical depth observations in the Arctic between 1991 and 1999, J. Geophys. Res.-Atmos., 107, AAC6.1-AAC6.13, doi:10.1029/2001JD000536, 2002.

Hoffmann, A., Ritter, C., Stock, M., Maturilli, M., Eckhardt, S., Herber, A., and Neuber, R.: Lidar measurements of the Kasatochi aerosol plume in August and September 2008 in Ny-Ålesund, Spitsbergen, J. Geophys. Res., 115, D00L12, doi:10.1029/2009JD013039, 2010.

Holben, B. N., Eck, T. F., Slutsker, I., Tanré, D., Buis, J. P., Setzer, A., Vermote, E., Reagan, J. A., Kaufman, Y. J., Nakajima, T., Lavenu, F., Jankowiak, I., and Smirnov, A.: \{AERONET\} - 
A Federated Instrument Network and Data Archive for Aerosol Characterization, Remote Sens. Environ., 66, 1-16, 1998.

Inoue, J., Liu, J., Pinto, J. O., and Curry, J. A.: Intercomparison of Arctic Regional Climate Models: Modeling Clouds and Radiation for SHEBA in May 1998, J. Climate, 19, 4167-4178, doi:10.1175/JCLI3854.1, 2006.

Intrieri, J. M. and Shupe, M. D.: Characteristics and radiative effects of diamond dust over the western Arctic Ocean region, J. Climate, 17, 2953-2960, doi:10.1175/15200442(2004)017<2953:CAREOD>2.0.CO;2, 2004.

Ivanescu, L.: Une application de la photométrie stellaire à l'observation de nuages optiquement minces à Eureka, NU (An application of starphotometry to observations of optically thin clouds at Eureka, NU), MSc thesis, Université de Sherbrooke, Sherbrooke, Canada, 2015 (in French).

Ivanescu, L., O’Neill, N. T., Blanchet, J.-P., Baibakov, K., and Duck, T.: Star-photometers and Ground-based Lidars to evaluate Caliop during the Arctic night, Cloudsat/CALIPSO Science Team Meeting, Montreal, Canada, 2011.

Jacob, D. J., Crawford, J. H., Maring, H., Clarke, A. D., Dibb, J. E., Emmons, L. K., Ferrare, R. A., Hostetler, C. A., Russell, P. B., Singh, H. B., Thompson, A. M., Shaw, G. E., McCauley, E., Pederson, J. R., and Fisher, J. A.: The Arctic Research of the Composition of the Troposphere from Aircraft and Satellites (ARCTAS) mission: design, execution, and first results, Atmos. Chem. Phys., 10, 5191-5212, doi:10.5194/acp-10-5191-2010, 2010.

Kattsov, V. M. and Källén, E.: 4. Future climate change: modeling and scenarios for the Arctic, in: Arctic Climate Impact Assessment, Cambridge University Press, Cambridge, UK and New York, NY, USA, 2005..

Kerzenmacher, T. E.: Measurements of $\mathrm{O}_{3}, \mathrm{NO}_{2}$ and temperature during the 2004 Canadian Arctic ACE Validation Campaign, Geophys. Res. Lett., 32, L16S07, doi:10.1029/2005GL023032, 2005

Klett, J. D.: Stable analytical inversion solution for processing lidar returns, Appl. Optics, 20, 211-20, doi:10.1364/AO.20.000211, 1981.

Leiterer, U., Naebert, A., Naebert, T., and Alekseeva, G.: A new star photometer developed for spectral aerosol optical thickness measurements in Lindenberg, Contrib. Atmos. Phys., 68, 133141, 1995.

Lesins, G., Bourdages, L., Duck, T. J., Drummond, J. R., Eloranta, E. W., and Walden, V. P.: Large surface radiative forcing from topographic blowing snow residuals measured in the High Arctic at Eureka, Atmos. Chem. Phys., 9, 1847-1862, doi:10.5194/acp-9-1847-2009, 2009.

Lesins, G., Duck, T. J., and Drummond, J. R.: Climate trends at Eureka in the Canadian high arctic, Atmos. Ocean, 48, 59-80, doi:10.3137/AO1103.2010, 2010.

Manney, G. L., Santee, M. L., Rex, M., Livesey, N. J., Pitts, M. C., Veefkind, P., Nash, E. R., Wohltmann, I., Lehmann, R., Froidevaux, L., Poole, L. R., Schoeberl, M. R., Haffner, D. P., Davies, J., Dorokhov, V., Gernandt, H., Johnson, B., Kivi, R., Kyro, E., Larsen, N., Levelt, P. F., Makshtas, A., McElroy, C. T., Nakajima, H., Parrondo, M. C., Tarasick, D. W., von der Gathen, P., Walker, K. A., and Zinoviev, N. S.: Unprecedented Arctic ozone loss in 2011, Nature, 478, 469-475, doi:10.1038/nature10556, 2011.

McFarquhar, G. M., Ghan, S., Verlinde, J., Korolev, A., Strapp, J. W., Schmid, B., Tomlinson, J. M., Wolde, M., Brooks, S. D., Cz- iczo, D., Dubey, M. K., Fan, J., Flynn, C., Gultepe, I., Hubbe, J., Gilles, M. K., Laskin, A., Lawson, P., Leaitch, W. R., Liu, P., Liu, X., Lubin, D., Mazzoleni, C., Macdonald, A.-M., Moffet, R. C., Morrison, H., Ovchinnikov, M., Shupe, M. D., Turner, D. D., Xie, S., Zelenyuk, A., Bae, K., Freer, M., and Glen, A.: Indirect and Semi-direct Aerosol Campaign, B. Am. Meteorol. Soc., 92, 183-201, doi:10.1175/2010BAMS2935.1, 2011.

Menut, L., Flamant, C., Pelon, J., and Flamant, P. H.: Urban Boundary-Layer Height Determination from Lidar Measurements Over the Paris Area, Appl. Opt., 38, 945-954, doi:10.1364/AO.38.000945, 1999.

Moritz, R. E., Bitz, C. M., and Steig, E. J.: Dynamics of recent climate change in the Arctic, Science, 80, 1497-1502, doi:10.1126/science.1076522, 2002.

Nott, G. J., Duck, T. J., Doyle, J. G., Coffin, M. E. W., Perro, C., Thackray, C. P., Drummond, J. R., Fogal, P. F., McCullough, E., and Sica, R. J.: A remotely operated lidar for aerosol, temperature, and water vapor profiling in the high Arctic, J. Atmos. Ocean. Tech., 29, 221-234, doi:10.1175/JTECH-D-11-00046.1, 2012.

O'Neill, N. T.: On $\mathrm{NO}_{2}$ optical depths in the visible, Internal AERONET memo, GSFC/NASA, 1999.

O’Neill, N. T., Eck, T. F., Smirnov, A., Holben, B. N., and Thulasiraman, S.: Spectral discrimination of coarse and fine mode optical depth, J. Geophys. Res.-Atmos., 108, AAC8.1-AAC8.15, doi:10.1029/2002JD002975, 2003.

O’Neill, N. T., Pancrati, O., Baibakov, K., Eloranta, E., Batchelor, R. L., Freemantle, J., McArthur, L. J. B., Strong, K., and Lindenmaier, R.: Occurrence of weak, sub-micron, tropospheric aerosol events at high Arctic latitudes, Geophys. Res. Lett., 35, L14814, doi:10.1029/2008GL033733, 2008a.

O’Neill, N. T., Eck, T. F., Smirnov, A., N., H. B., and Thulasiraman, S.: Spectral deconvolution algorithm technical memo, AERONET project, NASA/GSFC, available at: http://aeronet. gsfc.nasa.gov/new_web/publications.html (Section "Deconvolution Algorithm Description”, last access: 1 December 2014), 2008b.

O’Neill, N. T., Perro, C., Saha, A., Lesins, G., Duck, T. J., Eloranta, E. W., Nott, G. J., Hoffman, A., Karumudi, M. L., Ritter, C., Bourassa, A., Abboud, I., Carn, S. A., and Savastiouk, V.: Properties of Sarychev sulphate aerosols over the Arctic, J. Geophys. Res.-Atmos., 117, D04203, doi:10.1029/2011JD016838, 2012.

Pérez-Ramírez, D., Ruiz, B., Aceituno, J., Olmo, F. J., and AladosArboledas, L.: Application of Sun/star photometry to derive the aerosol optical depth, Int. J. Remote Sens., 29, 5113-5132, doi:10.1080/01431160802036425, 2008a.

Pérez-Ramírez, D., Aceituno, J., Ruiz, B., Olmo, F. J., and AladosArboledas, L.: Development and calibration of a star photometer to measure the aerosol optical depth: smoke observations at a high mountain site, Atmos. Environ., 42, 2733-2738, doi:10.1016/j.atmosenv.2007.06.009, 2008b.

Pérez-Ramírez, D., Lyamani, H., Olmo, F. J., Whiteman, D. N., Navas-Guzmán, F., and Alados-Arboledas, L.: Cloud screening and quality control algorithm for star photometer data: assessment with lidar measurements and with all-sky images, Atmos. Meas. Tech., 5, 1585-1599, doi:10.5194/amt-5-1585-2012, 2012.

Prenni, A. J., DeMott, P. J., Kreidenweis, S. M., Harrington, J. Y., Avramov, A., Verlinde, J., Tjernström, M., Long, C. N., 
and Olsson, P. Q.: Can ice-nucleating aerosols affect Arctic seasonal climate?, B. Am. Meteorol. Soc., 88, 541-550, doi:10.1175/BAMS-88-4-541, 2007.

Quinn, P. K., Shaw, G., Andrews, E., Dutton, E. G., Ruoho-Airola, T., and Gong, S. L.: Arctic haze: current trends and knowledge gaps, Tellus B, 59, 99-114, doi:10.3402/tellusb.v59i1.16972, 2007.

Russell, P., Livingston, J., Schmid, B., Eilers, J., Kolyer, R., Redemann, J., Ramirez, S., Yee, J.-H., Swartz, W., Shetter, R., Trepte, C., Risley Jr., A., Wenny, B., Zawodny, J., Chu, W., Pitts, M., Lumpe, J., Fromm, M., Randall, C., Hoppel, K., and Bevilacqua, R.: Aerosol optical depth measurements by airborne sun photometer in SOLVE II: Comparisons to SAGE III, POAM III and airborne spectrometer measurements, Atmos. Chem. Phys., 5, 1311-1339, doi:10.5194/acp-5-1311-2005, 2005.

Saha, A., O’Neill, N. T., Eloranta, E., Stone, R. S., Eck, T. F., Zidane, S., Daou, D., Lupu, A., Lesins, G., Shiobara, M., and McArthur, L. J. B.: Pan-Arctic sunphotometry during the ARCTAS-A campaign of April 2008, Geophys. Res. Lett., 37, L05803, doi:10.1029/2009GL041375, 2010.

Schmale, J., Schneider, J., Ancellet, G., Quennehen, B., Stohl, A., Sodemann, H., Burkhart, J. F., Hamburger, T., Arnold, S. R., Schwarzenboeck, A., Borrmann, S., and Law, K. S.: Source identification and airborne chemical characterisation of aerosol pollution from long-range transport over Greenland during POLARCAT summer campaign 2008, Atmos. Chem. Phys., 11, 1009710123, doi:10.5194/acp-11-10097-2011, 2011.

Shaw, G. E.: Sun photometry, B. Am. Meteorol. Soc., 64, 4-10, doi:10.1175/1520-0477(1983)064<0004:SP>2.0.CO;2, 1983.

Shaw, G. E., Reagan, J. A., and Herman, B. M.: Investigations of atmospheric extinction using direct solar radiation measurements made with a multiple wavelength radiometer, J. Appl. Meteorol., 12, 374-380, 1973.

Smirnov, A., Holben, B. N., Eck, T. F., Dubovik, O., and Slutsker, I.: Cloud screening and quality control algorithms for the AERONET database, Remote Sens. Environ., 73, 337-349, 2000.

Spiegel, M. R.: Statistics, Schaum's Outline Series in Mathematics, McGraw-Hill, Toronto, 1961.

Steinbring, E., Ward, W., and Drummond, J. R.: Astronomical sky quality near Eureka, in the Canadian High Arctic, Publ. Astron. Soc. Pacific 124, no. 912, 185-194, 2012.

Stock, M., Ritter, C., Herber, A., von Hoyningen-Huene, W., Baibakov, K., Gräser, J., Orgis, T., Treffeisen, R., Zinoviev, N., Makshtas, A., and Dethloff, K.: Springtime Arctic aerosol: Smoke versus haze, a case study for March 2008, Atmos. Environ., 52, 48-55, doi:10.1016/j.atmosenv.2011.06.051, 2012.

Stone, R. S., Anderson, G. P., Shettle, E. P., Andrews, E., Loukachine, K., Dutton, E. G., Schaaf, C., and Roman, M. O.: Radiative impact of boreal smoke in the Arctic: observed and modeled, J. Geophys. Res., 113, D14S16, doi:10.1029/2007JD009657, 2008.

Stroeve, J. C., Serreze, M. C., Holland, M. M., Kay, J. E., Malanik, J., and Barrett, A. P.: The Arctic's rapidly shrinking sea ice cover: a research synthesis, Climatic Change, 110, 10051027, doi:10.1007/s10584-011-0101-1, 2011.
Thomason, L. W., Herman, B. M., and Reagan, J. A.: The effect of atmospheric attenuators with structured vertical distributions on air mass determinations and Langley plot analyses, J. Atmos. Sci., 40, 1851-1854, doi:10.1175/15200469(1983)040<1851:TEOAAW>2.0.CO;2, 1983.

Tomasi, C., Vitale, V., Lupi, A., Di Carmine, C., Campanelli, M., Herber, A., Treffeisen, R., Stone, R. S., Andrews, E., Sharma, S., Radionov, V., von Hoyningen-Huene, W., Stebel, K., Hansen, G. H., Myhre, C. L., Wehrli, C., Aaltonen, V., Lihavainen, H., Virkkula, A., Hillamo, R., Ström, J., Toledano, C., Cachorro, V. E., Ortiz, P., de Frutos, A. M., Blindheim, S., Frioud, M., Gausa, M., Zielinski, T., Petelski, T., and Yamanouchi, T.: Aerosols in polar regions: A historical overview based on optical depth and in situ observations, J. Geophys. Res., 112, D16205, doi:10.1029/2007JD008432, 2007.

Uttal, T., Curry, J. A., Mcphee, M. G., Perovich, D. K., Moritz, R. E., Maslanik, J. A., Guest, P. S., Stern, H. L., Moore, J. A., Turenne, R., Heiberg, A., Serreze, M. C., Wylie, D. P., Persson, O. G., Paulson, C. A., Halle, C., Morison, J. H., Wheeler, P. A., Makshtas, A., Welch, H., Shupe, M. D., Intrieri, J. M., Stamnes, K., Lindsey, R. W., Pinkel, R., Pegau, W. S., Stanton, T. P., and Grenfeld, T. C.: Surface Heat Budget of the Arctic Ocean, B. Am. Meteorol. Soc., 83, 255-275, doi:10.1175/15200477(2002)083<0255:SHBOTA>2.3.CO;2, 2002.

Verlinde, J., Harrington, J. Y., Yannuzzi, V. T., Avramov, A., Greenberg, S., Richardson, S. J., Bahrmann, C. P., McFarquhar, G. M., Zhang, G., Johnson, N., Poellot, M. R., Mather, J. H., Turner, D. D., Eloranta, E. W., Tobin, D. C., Holz, R., Zak, B. D., Ivey, M. D., Prenni, A. J., DeMott, P. J., Daniel, J. S., Kok, G. L., Sassen, K., Spangenberg, D., Minnis, P., Tooman, T. P., Shupe, M., Heymsfield, A. J., and Schofield, R.: The Mixed-Phase Arctic Cloud Experiment, B. Am. Meteorol. Soc., 88, 205-221, doi:10.1175/BAMS-88-2-205, 2007.

Wandinger, U. and Ansmann, A.: Experimental determination of the lidar overlap profile with Raman Lidar, Appl. Optics, 41, 511, doi:10.1364/AO.41.000511, 2002.

Wang, X. and Key, J. R.: Recent trends in Arctic surface, cloud, and radiation properties from space, Science, 299, 1725-1728, doi:10.1126/science.1078065, 2003.

Yamanouchi, T., Treffeisen, R., Herber, A., Shiobara, M., Yamagata, S., Hara, K., Sato, K., Yabuki, M., Tomikawa, Y., Rinke, A., Neuber, R., Schumachter, R., Kriews, M., Strom, J., Schrems, O., and Gernandt, H.: Arctic Study of Tropospheric Aerosol and Radiation (ASTAR) 2000: Arctic haze case study, Tellus B, 57, 141-152, doi:10.1111/j.1600-0889.2005.00140.x, 2005.

Young, C. L., Sokolik, I. N., and Dufek, J.: Regional radiative impact of volcanic aerosol from the 2009 eruption of Mt. Redoubt, Atmos. Chem. Phys., 12, 3699-3715, doi:10.5194/acp-12-36992012, 2012. 